NBER WORKING PAPER SERIES

\title{
DO DOMESTIC INVESTORS HAVE AN EDGE? \\ THE TRADING EXPERIENCE OF FOREIGN INVESTORS IN KOREA
}

\author{
Hyuk Choe \\ Bong-Chan Kho \\ René M. Stulz \\ Working Paper 10502 \\ http://www.nber.org/papers/w10502 \\ NATIONAL BUREAU OF ECONOMIC RESEARCH \\ 1050 Massachusetts Avenue \\ Cambridge, MA 02138 \\ May 2004
}

René Stulz is grateful for the hospitality of the Kellogg Graduate School of Management at Northwestern University and the George G. Stigler Center for the Study of the Economy and State at the University of Chicago where part of this research was conducted. We are grateful for comments from seminar participants at Duke, the Hong-Kong University of Science and Technology, the Ohio State University, the University of California at Los Angeles, the University of North Carolina, the University of Texas, the Hallym University, the American Economic Association meetings in Washington, and from Dong Lee, Mark Grinblatt, Campbell Harvey, Maureen O'Hara, Andrew Karolyi, Pete Kyle, Toby Moskowitz, Richard Roll, Mark Seasholes, Linda Tesar, and two anonymous referees. The views expressed herein are those of the author(s) and not necessarily those of the National Bureau of Economic Research.

(C)2004 by Hyuk Choe, Bong-Chan Kho, and René M. Stulz. All rights reserved. Short sections of text, not to exceed two paragraphs, may be quoted without explicit permission provided that full credit, including (C) notice, is given to the source. 
Do Domestic Investors Have an Edge? The Trading Experience of Foreign Investors in Korea Hyuk Choe, Bong-Chan Kho, and René M. Stulz

NBER Working Paper No. 10502

May 2004

JEL No. F36, G12, G14, G15

\title{
$\underline{\text { ABSTRACT }}$
}

We investigate whether domestic investors have an edge over foreign investors in trading domestic stocks.Using Korean data, we show that foreign money managers pay more than domestic money managers when they buy and receive less when they sell for medium and large trades. The sample average daily trade-weighted disadvantage of foreign money managers is of 21 basis points for purchases and 16 basis points for sales. There is also some evidence that domestic individual investors have an edge over foreign investors. The explanation for these results is that prices move more against foreign investors than against domestic investors before trades.

\author{
Hyuk Choe \\ Seoul National University \\ hchoe@snu.ac.kr \\ Bong-Chan Kho \\ Seoul National University \\ bkho@snu.ac.kr \\ René M. Stulz \\ Fisher College of Business, Ohio State University \\ 806A Fisher Hall \\ 2100 Neil Avenue \\ Columbus, OH 43210-1144
}


For a long time, the consensus among financial economists as well as among finance academics and practitioners has been that a country's domestic investors have an advantage in trading stocks in their country over foreign investors. A leading explanation for this advantage has been that domestic investors have superior information, but other explanations have been advanced also. For instance, it has been argued that regulators might be more tolerant of domestic investors or even biased against foreign investors. This view that domestic investors have an edge over foreign investors has been used to explain empirical regularities such as the home bias, the volatility of capital flows, and herding among foreign investors. However, recently, a number of papers have provided results that are inconsistent with this view. ${ }^{1}$

In this paper, we use a unique dataset to shed new light on the issue of whether domestic investors have an edge over foreign investors in trading domestic stocks by investigating whether foreigners pay more for stocks when they buy and receive less when they sell. One advantage of such an investigation is that it relies less on models of expected returns than existing papers that compare the performance of foreign investors to the performance of domestic investors. Using a dataset of all trades on the Korean stock exchange from December 2, 1996 to November 30, 1998, we find evidence that foreign investors are at a disadvantage for medium and large trades but not for small trades. Weighting trades by their size, the average disadvantage of foreign money managers relative to domestic money managers is of the order of 21 basis points for purchases and 16 basis points for sales. This means that on a roundtrip trade foreign money managers face greater transaction costs of the order of 37 basis points compared to domestic money managers, which is substantial for any foreign investor who is not a long-term buy-and-hold investor. For instance, an investor who trades three times per year would contemplate a drag on his performance in excess of 100 basis points. To put this in perspective, Carhart (1997) reports that the difference in the monthly estimates of Jensen's alpha between the top decile and the bottom decile of

\footnotetext{
${ }^{1}$ See, for instance, Grinblatt and Keloharju (2000), Seasholes (2000), and Froot and Ramadorai (2001).
} 
diversified mutual funds in the U.S. is $0.67 \%$ from 1963 through 1993 . The roundtrip edge could therefore have a substantial impact on the performance of a money manager. We also find that foreign money managers are at a disadvantage compared to domestic individuals, but this evidence is stronger for sales than for purchases.

We find that the disadvantage of foreign investors cannot be explained by firm and stock characteristics. It is strongly related to the size of the trades of foreign investors and to how intensely they trade. There are at least three non-mutually exclusive explanations for this result. First, foreign investors could be more impatient or trade when liquidity is lower, so that they pay more to liquidity providers. Second, foreign investors are better informed, so that their trades have a larger permanent impact. Third, they make their trades after prices have already moved against them. To investigate these three possible explanations, we investigate stock returns before, during, and after periods of intensive trading. We find that the intensive trading by foreign investors is not associated with a greater temporary impact than the intensive trading by domestic institutions, suggesting that foreign investors are not more impatient in their trading than domestic institutions. Using a conventional measure of the permanent impact of intensive trading, there is no evidence either that foreign investors are better informed than domestic institutions. The key difference between foreign investors and domestic investors is that prices move unfavorably for foreign investors than for domestic investors immediately before they trade intensively. This difference is partly explained by the return-chasing behavior of foreign investors.

As far as we know, this is the first paper that compares in any country the prices domestic and foreign investors pay or receive when they trade. More effort has been expended on understanding whether foreigners earn more or less than domestic investors on their investments in stocks. Studies that evaluate investment performance face the problem that their results are sensitive to how they control for priced risk. In contrast, when comparing prices within a calendar day, control for risk priced in asset pricing models is 
not important, so that the conclusions one reaches do not depend on the choice and parameters of asset pricing models.

The controls for risk may partly explain why there is no agreement in the literature on whether foreigners perform better than domestic investors and on whether domestic investors have an information advantage. Interestingly, when Dvorak (2002) implements our approach for Indonesia, he also finds that foreign investors are at a disadvantage. Hau (2001) investigates trading data for professional investors. In his work, he shows that local investors perform better than other investors. However, his paper is focused on professional investors only and looks at the performance of traders over time rather than whether they buy or sell at advantageous prices. Other papers look at the performance of foreign investors compared to the performance of domestic investors over periods of various lengths. Grinblatt and Keloharju (2000) and Seasholes (2000) argue that as a result of their better access to expertise and talent, foreign institutions should perform better than domestic institutions. Using daily data for the 16 largest Finnish stocks, Grinblatt and Keloharju (2000) find that over a two-year period foreigners and domestic financial corporations buy more stocks that perform well over the next 120 trading days than domestic individual investors, but their sample period is too short for them to conduct a study of holding period returns. Seasholes (2000) finds that foreign investors buy (sell) ahead of good (bad) earnings announcements in Taiwan while domestic investors do the opposite. Froot, O'Connell, and Seasholes (2001) and Froot and Ramadorai (2001) use flow data to show that foreign investors trade ahead of better returns. These papers are consistent with better information and greater sophistication on the part of foreign investors. However, evidence on the performance of foreign investors is mixed. For instance, Shukla and van Inwegen (1995) show that U.K. money managers underperform American money managers when picking U.S. stocks. Kang and Stulz (1997) using annual data for 18 years find no evidence that foreign investors outperform domestic investors in Japan. Coval and Moskowitz (1999), using only U.S. stock returns, provide 
evidence that investor location matters, in that mutual fund managers are better at picking stocks of firms that are close to where they are than stocks of firms from a more distant location.

Throughout the paper, we compare foreign investors to both domestic institutional investors and domestic individuals. Such a comparison is important for two reasons. First, foreign investors are mostly institutional investors. Consequently, we have to understand whether foreign investors differ from domestic investors as a group because they are foreign or simply because they are institutional investors. Second, in emerging markets, domestic institutional investors are not as important as they are in developed markets and their actions may at times be affected by political considerations. As suggested by some authors (Seasholes, 2000, and Grinblatt and Keloharju, 2000), foreign investors may have an advantage over domestic institutions simply because their personnel is more experienced, has access to more proprietary research, and does not have to worry about trading to fulfill political objectives or to help out related companies.

The paper proceeds as follows. In Section 1, we introduce our data. In Section 2, we compare the prices at which various investor types trade, and the determinants of the trade price differences between domestic and foreign investors are examined in Section 3. In Section 4, we compare the price impact and the performance of intensive trading for domestic and foreign investors. We conclude in Section 5.

\section{The Korea Stock Exchange and Sample Construction}

Over our sample period, the Korea Stock Exchange (KSE) holds two trading sessions on each weekday: a morning session and an afternoon session. Batch auctions are used three times a day to determine the opening prices of each session and the daily closing prices. The batch auction price for a stock is the same for all investors, so that foreign investors cannot be at a disadvantage compared to domestic investors when they trade in a batch auction. There are no trades during the last 10 minutes of each day, when orders are collected for the closing batch auction. Trading prices during the rest of the trading hours are 
determined by continuous (or non-batch) auction. During our sample period, there is a morning session on Saturdays. The KSE does not have designated market makers. Buyers and sellers meet via the Automated Trading System (ATS). Before November 25, 1996, only limit orders were allowed, but since then market orders are allowed as well.

The database we use includes all transactions on the KSE for the period from December 2, 1996 to November 30, 1998, which is compiled by the Institute of Finance and Banking (IFB) at Seoul National University. This database has each order time-stamped as of the time that it arrives at the exchange and as of the time that the order is executed. The data provide information on the country of residence of investors as well as on whether they are individuals or institutions. Institutions are further classified into various types of institutions, such as securities firms, mutual funds, banks, and insurance companies. Foreign investors in Korea have to register with the Financial Supervisory Service (FSS) and obtain an ID number before they can start trading stocks. Through this ID number, the FSS makes sure that the foreign ownership limit for each company and each foreign investor is not exceeded by informing the KSE whether a foreign order satisfies the company and investor limits. The ownership limit for each individual foreign investor was 5\% of a firm's shares until May 2, 1997, when it increased to 6\%. It then increased to $7 \%$ on November 3,1997 , and to $50 \%$ on December 11,1997 . In addition, foreign investors as a group could not own more than $20 \%$ of a firm's shares before May 1, 1997. This aggregate ownership limit on foreign investors increased to $23 \%$ on May 2,1997 , to $26 \%$ on November 3,1997 , to $50 \%$ on December 11,1997 , to $55 \%$ on December 30,1997 , and finally to $100 \%$ on May 25,1998 . One limitation of the foreign ownership database is that it is possible that trades we identify as foreign trades are actually trades by Korean investors who set up a foreign nominee company to trade on the KSE.

Our database only allows us to know the type of investor who participates in the transaction. We are not allowed to know the identity of the investor who buys or sells a stock in a particular transaction. This 
limitation of our database prevents us from tracking the holdings or trades of specific investors. We have no way of knowing whether one investor bought a stock multiple times in a day or only one time.

We have detailed ownership information for 1998. At the end of 1998, foreign investors owned 18\% of the capitalization of Korean stocks. Domestic banks owned $7.30 \%$ of the Korean stock market, while domestic money managers owned $6.30 \%$. These domestic institutional investors owned a smaller fraction of the Korean stock market than foreign investors. Korean corporations owned $19.80 \%$ of the market, while the government and government-owned firms owned $19.70 \%$ of the market. Finally, individuals owned $28.90 \%$ of the market. Compared to Western countries, few individuals owned stocks directly since only $4.1 \%$ of Korean domestics were investors in the market.

Most of the trading in the Korean stock market is done by individual investors. In $1998,77.43 \%$ of the gross value of stock sales was by domestic individual investors. In contrast, $5.9 \%$ of the gross value of stock sales was by foreign investors and $13.71 \%$ was by domestic institutional investors. The gross stock sales by the government and by corporations together represented only $2.88 \%$ of the gross stock sales. The fact that the trading of the government and of corporations represents such a small fraction of the overall trading explains why we ignore it in our study. With this data, domestic investors are more active traders than foreign investors and domestic individuals are more active traders than domestic institutions. This contrasts with the results of Tesar and Werner (1995) for more developed countries, where foreign investors are more active traders than local investors. In Korea, foreign investors sell stocks for a gross amount equal to $47 \%$ of their end-of-year ownership, while domestic individual investors sell stocks for a gross amount equal to $381 \%$ of their end-of-year ownership. Domestic institutions sell stocks for a gross amount of $143 \%$ of the value of their end-of-year holdings. Foreign investors are mostly institutions, so that foreign institutions trade much less in Korea than domestic institutions.

Table 1 provides another way to look at the relative importance of individuals, domestic institutions, and foreign investors in the trading of Korean stocks. In this table, we divide up the day in hourly periods. 
We see that individual investors account for more than half of the value of the stocks traded in each period in the table. Except for the afternoon opening batch and the closing batch, the value of trades by foreign investors is lower than the value of trades by domestic institutions.

Figure 1 shows the cumulative net flows of various investor groups over our sample period against the backdrop of the ownership limit and the performance of the Korea stock market. Over the sample period, foreign investors never have net negative cumulative flows and neither do individual investors. Both foreign investors and Korean individual investors accumulate holdings of Korean stocks over the sample period by buying from Korean financial institutions that are net sellers over our sample period. This figure puts in perspective the impact of the Asian crisis on holdings of Korean stocks by foreign investors. Though foreign investors sold stocks at the height of the crisis, they did not sell enough to make their ownership of the Korean stock market fall below what it had been at the end of 1996. Since the Korean stock market experienced dramatic changes during our sample period, we control for market conditions in our regressions.

Over our sample period there are three Korean ADRs trading on the NYSE in addition to the Korea Fund. At the end of 1996, the shares corresponding to the ADRs represent a small fraction of the outstanding shares of the firms that have issued ADRs (2.3\% for Kepco, 5.2\% for Posco, and 1.8\% for SK Telecom). Our data exclude New York trading. At most, New York trading may affect the results for three stocks.

\section{Do Foreign Investors Trade at Worse Prices?}

In this section, we investigate whether the various investor types trade at different prices. We include in our sample all days during which foreign investors traded a stock. This means that we estimate whether foreign investors are at a disadvantage given that they trade. Our approach does not, therefore, address the extent to which foreign investors are at a disadvantage unconditionally. We do not attempt to estimate 
what their disadvantage would be on days and for stocks where the disadvantage is large enough to make it uneconomical for foreign investors to trade.

Define $P_{i}^{d t}$ as the price of stock $i$ on day $d$ for trade $t$ and $V_{i}^{d t}$ as the number of shares of the trade for stock $i$ on day $d$ for trade $t$. We first compute the volume-weighted average price - this is what the practitioners call "bwap," the buy weighted-average price - using all trades on that day:

$$
A_{i}^{d}=\frac{\sum_{t} P_{i}^{d t} V_{i}^{d t}}{\sum_{t} V_{i}^{d t}}
$$

We then compute the volume-weighted average price for all purchases and sales separately for each investor type we are interested in:

$$
B_{i, j}^{d}=\frac{\sum_{t} P_{i, j}^{d t} V_{i, j}^{d t}}{\sum_{t} V_{i, j}^{d t}}
$$

where the subscript $j$ denotes the investor class $j$. We consider split trades originated from one order as one trade. We finally compute the price ratio, $B_{i, j}^{d} / A_{i}^{d}$, for all purchases (or sales) by investors of type $j$ for stock $i$ on a given day $d$. A price ratio greater than one for the purchases of an investor type means that this investor type buys on average at a price above the average price on that day. Everything else equal, a type of investors is disadvantaged relative to another type of investors for purchases if investors of the first type buy at a higher price than the investors of the second type. Similarly, a type of investors that sells at a lower price than another type of investors is at a disadvantage relative to that type of investors. Studies that investigate trading costs compare prices paid to the average price on a day, to the closing price, or to the previous day closing price. Even though price ratios are sensitive to the price in the denominator of the price ratio, the difference in price ratios is not since the price in the denominator affects both price ratios similarly. Our results are the same when we compute the difference in price ratios using the previous day closing price in the denominator. Though we report price ratios for purchases and 
sales, we therefore focus our study on differences in price ratios since they offer a measure how one type of investors is disadvantaged relative to another type. In the remainder of this section, we first provide evidence on differences in the price ratios over our sample period for the various investor classes for buy and sell trades. We then investigate the determinants of these differences across stocks using crosssectional regressions in the next section.

The equally-weighted average of the price ratios across stocks and days for each investor type is shown in Panel A of Table 2. We report results separately for domestic and foreign individuals, money managers, and banks. We do not report results for resident foreign investors, government and corporate holdings because their economic importance is trivial. For example, for foreign money managers, the price ratio gives us the equally-weighted average across stocks and days of the volume-weighted average price at which they bought stocks normalized by the volume-weighted average price at which the stocks traded on the days. Foreign money managers are the foreign investors who trade the largest number of stocks on a given day. We focus on them in most of our discussion of the table. Looking at the foreign money managers, the ratio (multiplied by 100) is 99.988 using all observations, which is insignificantly different from 100. This means that foreign money managers do not trade at prices significantly different from the average price in a day. They buy stocks, however, at significantly higher prices than Korean individuals. The price ratio for foreign investors is higher than the price ratio of Korean individual investors by 0.151 with a t-statistic of 10.50 . This means that foreign money managers buy stocks at a price that is on average $0.15 \%$ greater than the average daily price paid by Korean individual investors. In contrast, there is no difference in the price that foreign money managers pay relative to the price domestic money managers pay.

The problem with comparing prices paid across all trade sizes is that we might be comparing prices paid on large trades by foreign investors to small trades made by domestic individuals and/or institutions. For instance, it could be that domestic individuals make more small trades and that the prices for these 
trades are more advantageous. To examine the impact of trade size on our results, we divide trades into small, medium, and large trades. This reduces the number of stocks used in the comparisons since for each comparison we are adding a constraint to the sample that trades must be in the same size category. Small trades are trades for less than 5M won, while medium trades are between 5M and 50M won, and large trades are trades for more than $50 \mathrm{M}^{2}{ }^{2}$ Small trades are overwhelmingly made by domestic individuals during our sample period. $53.9 \%$ of daily total trades are small trades by individuals. Another $29.96 \%$ of daily trades are medium-size trades by individuals. The small and medium trades of foreign investors represent $1.93 \%$ and $3.60 \%$, respectively, of daily trades.

We find that there is no evidence that foreign money managers are at a disadvantage for small-size trades. They trade at the same prices as individuals and at better prices than domestic money managers. However, foreign money managers trade at worse prices than domestic individuals and money managers for medium trades and than domestic money managers for large trades. Strikingly, domestic money managers pay significantly lower prices for large purchase trades than either domestic individual investors or foreign investors. In particular, domestic money managers pay $0.143 \%$ less than foreign money managers with a t-statistic of 5.27 .

Let's now turn to Panel B of Table 2, where we show results for the selling trades of investors. The average selling price ratio for foreign money managers is significantly below one, so that they sell at a lower price than the average price during the day. For the whole sample, foreign investors sell at worse prices than domestic individuals, but not than domestic money managers. When we split trades according to their size, we find that foreign money managers are at a disadvantage for medium and large trades compared to both domestic individuals and institutions. For small trades, they sell at worse prices than individuals but at better prices than domestic institutions.

\footnotetext{
${ }^{2}$ The 5 million won is roughly equivalent to US\$4,200 at the exchange rate of 1,200 won per US\$. The cutoff in won value rather than in shares is chosen to control for the wide differences in prices across stocks in Korea.
} 
In Panel $\mathrm{C}$ of Table 2 we compare trade-value weighted price ratios. This approach weighs the daily price ratios across stocks on a given day using the value of the daily trades, so that more weight is given to stocks where foreign investors trade more intensively when computing the average price ratio. With this measure, foreign money managers have a disadvantage relative to domestic money managers of $0.212 \%$ when they buy and of $0.163 \%$ when they sell for the whole sample. The disadvantage of foreign money managers is slightly higher when the comparison is limited to the largest trades. Foreign money managers also have a substantial disadvantage relative to domestic individual investors when we use trade-weighted averages. All these differences are statistically significant.

Our sample period includes the East Asian crisis. Consequently, stock prices fall dramatically and then increase sharply during our sample period. Further, regulations change also during our period. For instance, the limit on foreign holdings increases. Index futures trading becomes more important throughout our sample period. Finally, index options trading is introduced in July 1997. Figure 2 shows a time-series plot of the price ratio differences. As can be seen from both panels of the figure, there is no evidence that the phenomenon we document is related to the East Asian crisis or that derivatives trading and regulatory changes reduce the disadvantage of foreign investors relative to domestic investors. This disadvantage seems pervasive through time. We also examine the main days of the crisis. We select seven two-day periods during the crisis that are associated with major events. ${ }^{3}$ There is no clear evidence that foreign investors are at a disadvantage when they sell on these days compared to domestic individuals and they seem to be at an advantage compared to domestic institutions. Consequently, these days play no significant role in our overall results.

\footnotetext{
${ }^{3}$ The events we selected are: 1) currency devaluation on 11/17/97 in Korean time (Event days $=11 / 15 / 97$ and 11/17/97); 2) seek for IMF help on 11/21/97 in Korean time (Event days $=11 / 20 / 97$ and 11/21/97); 3) resume talks on rescue package on 12/01/97 in New York time (Event days =12/01/97 and 12/02/97); 4) agreed on terms of the rescue package on 12/04/97 in New York time (Event days =12/04/97 and 12/05/97); 5) speed up delivery of the rescue loan on 12/15/97 in New York time (Event days $=12 / 15 / 97$ and 12/16/97); 6) rollover short-term bank debt on 12/30/97 in New York time (Event days $=01 / 03 / 98$ and 01/05/98); 7) agreed new loans to Korean banks on $01 / 29 / 98$ in New York time (Event days $=01 / 30 / 98$ and 01/31/98).
} 
An alternate approach to investigate whether the results are due to bad days for the Korean market is to split the days into quintiles of stock market performance. We find that, for every quintile, foreign investors buy at a significantly higher price than domestic individuals and at an insignificantly lower price than domestic institutions. For the worst quintile of market performance, foreign investors who sell receive less than domestic institutions. In contrast, they receive more than domestic institutions for the best quintile of market performance. The same results hold if, instead of splitting the sample into market performance quintiles, we split the sample into foreign exchange performance quintiles. For foreign exchange performance, the result is stronger when we compare foreign investors to domestic individuals: foreign investors pay more when they buy on days of high depreciation of the won and receive less when they sell on days of high depreciation of the won.

\section{The Determinants of Trade Prices.}

In the previous section, we saw that foreign investors are at a disadvantage relative to domestic investors. In this section, we investigate whether this disadvantage can be explained by firm and stock characteristics using multiple regressions. If foreign investors are less well-informed as is commonly believed, it should be that their disadvantage can be explained by firm and stock characteristics that proxy for information asymmetries since their disadvantage should be greater for stocks where information asymmetries are greater. Further, if differences in trading styles explain the disadvantage of foreign investors, then variables that proxy for when foreign investors are more likely to trade compared to domestic investors should explain their disadvantage. For instance, if foreign investors are more likely to trade in a stock when it has become relatively less liquid, they will trade at worse prices. In particular, we know from earlier research that foreign investors tend to be momentum investors. ${ }^{4}$ Keim (2003) shows

\footnotetext{
${ }^{4}$ For Korea, see Choe, Kho, and Stulz (1999).
} 
that momentum investors have a higher price impact than other investors because, as he puts it, they "paddle against the current," as they buy when the stock price is increasing and sell when it is falling.

Panel A of Table 3 provides descriptive statistics for the explanatory variables used in the multiple regressions. We use trade-size dummies in our regressions to investigate whether trade price differences between domestic and foreign investors depend on trade size. We then control for stock characteristics, stock returns, and the market return. It is often argued that information asymmetries fall as firms get larger. Further, firms with better growth opportunities or a lower book-to-market ratio may have more information asymmetries because intangible assets are harder to assess. If foreign investors are at a disadvantage when trading stocks where information asymmetries are more important, one would expect the difference between domestic and foreign investor trade prices to fall as the market value of the firm's equity increases (lsize) and fall as the book-to-market ratio increases (btm). If foreign investors are more impatient in their buying when the return on the market is higher, perhaps because of momentum trading, and more impatient in their selling when the return on the market is lower, we should see a negative coefficient on the KOSPI index return (kret) on the same day. If foreign investors are momentum traders, they are more likely to buy if the return of the stock in the recent past (ctc5) is high, if the overnight return (cto) is high, and if the contemporaneous open to close return (otc) is high. Since foreign investors are more likely to be momentum traders than domestic individuals and since the intensity of their momentum trading may differ from the intensity of the momentum trading of domestic institutions, we control for all these returns. Finally, we control for the average bid-ask spread prior to market close over the previous 30 trading days (avgbas), the stock's average volatility over the previous 30 trading days (avgsig), and the average turnover of the stock over the previous 30 trading days (avgturn). Specifically, the variables are constructed as follows:

- Firm characteristics and market return:

(1) lsize $=$ Log market value of equity on the previous day 
(2) $\mathrm{btm}=$ Book-to-market ratio on the previous day

(3) $\mathrm{kret}=$ KOSPI index return for the day (\%)

- Momentum-related characteristics:

(1) $\operatorname{ctc5}=$ Previous 5-day return (\%) (previous 6th day close to previous close)

(2) cto $=$ Overnight return $(\%)$ (previous close to opening price)

(3) otc $=$ Day-time return (\%) (opening to closing price)

- Trade-related characteristics that proxy for liquidity and execution costs:

(1) avgbas $=$ Average of previous 30 daily bid-ask spreads (at least 20 daily observations required $)$, where daily bid-ask spread $(\%)=($ ask-bid $) /[($ ask+bid $) / 2]$ prior to market close

(2) avgsig = Average of previous 30 daily volatilities (at least 20 daily observations required), where daily volatility $(\%)=($ high-low $) /[($ high + low $) / 2]$

(3) avgturn $=$ Average of previous 30 daily turnover ratios (at least 20 daily observations required), where daily turnover ratio $(\%)=$ total share trading volume for the day / total shares outstanding for the firm

(4) avgdf = Buy (or sell) trade value differences between two investor types for a stock-day / total trade value for the stock-day $(\%)$

In panel $\mathrm{B}$ of Table 3, we provide regression estimates from pooled regressions that use all observations throughout the sample period as well as from Fama-McBeth regressions. The advantage of the pooled regressions is that we can use the return on the market as an explanatory variable. The FamaMcBeth regressions take into account the cross-correlations and the serial correlation in the error term, so that the t-statistics are much more conservative. We use as the dependent variable the difference in price ratios of foreign investors from domestic individuals and domestic institutions, separately. All foreign investors are aggregated in one group, excluding resident foreign investors. We show two regression 
specifications for each comparison. The first comparison controls for trade size through the use of dummy variables for medium and large trades. Consequently, when estimating this regression, the dependent variable is the price ratio difference per stock day for a given trade size. The second comparison controls for the difference in traded value between the two types of investors. For that comparison, the dependent variable is the price ratio difference per stock day computed from all trades for that stock day.

The first four regressions compare price ratios for domestic individuals and foreign investors. The trade size dummy variables have significant coefficients in the pooled regression. In the Fama-McBeth regression, the coefficient on the size dummy variables is larger and more significant. Somewhat surprisingly, foreign investors face less favorable prices when trading in large firms after controlling for other variables. It might be that this is due to the fact that the coefficient on the size variable measures the relation between size and the price difference for a given bid-ask spread which might capture information asymmetries. ${ }^{5}$ Book-to-market is insignificant in two regressions and significant, but with opposite signs, in the other two regressions. The coefficient on the return of the Korean market is barely significant in the pooled regression. When we use the bid-ask spread as a proxy for information asymmetries and the turnover ratio as a proxy for liquidity, we see that foreign investors do worse trading stocks with greater information asymmetries and less liquidity. We also see that foreigners trade at better prices stocks that have performed well over the last five days and overnight. This result is surprising in light of Keim (2003) who shows that momentum trading has higher impact costs. His analysis does not, however, control for a stock's open-to-close return on the day of trading. To the extent that stocks that have performed well are more likely to have a high open-to-close return, controlling for open-to-close return could explain why the last five day return is not significant. We find that foreign investors perform worse for stocks that do well during the trading day. The next two regressions do not have the trade size dummy

\footnotetext{
${ }^{5}$ This explanation can explain the result for purchases, but for sales, the coefficient remains positive if we have no other control variables but size.
} 
variables. Instead, we control for the difference in trade value between investor types. The coefficient on the trade value difference is highly significant in both regressions. The clear message from the regressions is that foreign investors do worse when they buy more, either through larger trades or through more intensive trading. They also do worse on stocks with greater information asymmetries and higher sameday return.

In regressions (5) through (8), we investigate the determinants of the difference in price ratios between domestic institutional investors and foreign investors. In regressions (5) and (6), the trade size dummy variables have coefficients that are much larger than in regressions (1) and (2) and with extremely high t-statistics in the pooled regression, but lower t-statistics in the Fama-McBeth regressions. Regressions (7) and (8) show that coefficients on the difference in trade value are positive and significant in both regressions. Consequently, regressions (5) through (8) show that the disadvantage of foreign investors relative to domestic institutions increases when they buy more. The other coefficients are typically insignificant with the Fama-McBeth regressions, so that it is difficult to put much weight on those coefficients that are significant in the pooled regression except for the positive significant book-tomarket coefficient.

We now turn to the sell price ratios. Regressions (9) through (12) are for the difference in sell price ratios between domestic individual investors and foreign investors. As we would expect from the regressions for buy price ratios, foreign investors receive worse prices as they sell more. Most of the other coefficients have the opposite sign from the coefficients in the regressions for buy price ratios as we would expect. The only puzzling result is that the coefficients on the return for the previous five days and on the overnight return do not switch sign. Regressions (13) through (16) show that foreign investors receive less when they sell more compared to domestic institutions. Again, the other variables are typically not significant in the Fama-McBeth regressions. The coefficient on the difference in trade value by investor types is highly significant in economic terms. 


\section{The Price Impact of Intensive Buying and Selling by Investor Types}

So far, our evidence is that foreign investors are at a disadvantage compared to domestic investors for larger trades and when they trade more intensively than domestic investors. Another way to put this is that foreign investors are more at a disadvantage when they trade more. The previous section shows that this disadvantage cannot be explained by firm and stock characteristics. Why do foreign investors pay more and receive less when they trade more? A first possible explanation is that foreign investors are not at a disadvantage, but that they are more impatient than domestic investors when they trade intensely or trade when liquidity is lower. This greater impatience could be due to differences in liquidity concerns or because they have private information that is more short-lived than for domestic investors. A second potential explanation is that foreign investors are better informed, so that their trades have a greater permanent impact on prices. Finally, a third possible explanation is that the foreign investors trade at worse prices because prices have moved against them before they trade. This could be because they time trades poorly as a result of poor information, because they are taken advantage of in the trading process as a victim of front-running, or because they choose to trade after prices have moved as they follow intraday momentum strategies.

To investigate these possible explanations, we examine the intra-day returns before, during, and following periods of intense trading by domestic individual investors, domestic institutions, and foreign institutions. If foreign investors are more impatient, their trades should have more of a temporary impact relative to the trades of domestic investors. If they are better informed, they should have more of a permanent impact. Finally, if they trade at poor prices because prices moved against them before their trades, prices should increase more before they buy and less before they sell than they do for similar trades by domestic investors. 
In the remainder of this section, we first report estimates of the returns around periods of intensive trading by investor types. We then show that the differences in these returns between foreign investors and domestic investors cannot be explained simply by stock characteristics.

\subsection{The price impact of intra-day intensive trading by investor types}

To construct our sample of intra-day intensive trading, we use stocks for which we have at least 300 days with trading on the day and on the previous day. Further, we eliminate all stocks whose price falls below 1,000 won during the sample period. We end up with a sample of 512 stocks out of a possible 785 stocks. We then divide each week day into 47 five-minute intervals from 9:30 a.m. to 15:00 p.m., treating the time interval of 11:30 a.m. to 13:05 p.m. as a single interval containing the lunch break and similarly for the time interval of 14:50 p.m. to 15:00 p.m., which contains an order collection period for the close. For Saturdays, we have 23 five-minute periods. We look at returns for the 10 five-minute periods preceding the event and the 10 subsequent five-minute periods. We allow the sequence of five-minute periods to cross day boundaries. When they do, we count the overnight return as a five-minute period.

For each of the intervals for each of the 512 stocks over the sample period, we compute price-setting order imbalances by an investor type by subtracting the price-setting sell volume from the price-setting buy volume. We call a trade initiated by an investor type a price-setting trade by that investor type. A buy-side (sell-side) price-setting trade for foreign investors is a trade where the buy (sell) order of the foreign investors came after the sell-side (buy-side) order and hence made the trade possible. ${ }^{6} \mathrm{We}$ then select 10 intervals with the largest net buy price-setting imbalances and 10 intervals with the largest net sell price-setting imbalances for each stock and each investor type. For each of the selected events, we examine stock returns from the previous tenth (D-10) to the subsequent tenth $(\mathrm{D}+10)$ intervals

\footnotetext{
${ }^{6}$ For the batch auctions, we cannot identify who initiates a trade, and exclude them from the analysis here. For NYSE data, it is common to identify the initiating party of a trade using a tick test such as the one proposed by Lee and Ready (1991). There is no need for a tick test with our data because we know which party initiates the trade.
} 
surrounding the event. We report raw stock returns as well as returns adjusted for the sample average for the same day of the week and the same time interval.

We first consider the largest price-setting imbalances by foreign investors in Panel A of Table 4. A period of intensive buying follows a sequence of positive returns. From D-10 to D-1, the cumulative mean-adjusted return is $0.314 \%$ with a t-statistic of 7.42 . Net buy imbalances have a strong positive mean-adjusted return of $1.04 \%$ during the intense buying interval (D0). Interval (D+1) is still positive, but not significantly so. After that, there is a string of negative returns.

If the period of intensive trading leads to a greater price increase than the price increase in the longrun resulting from the information conveyed by the intensive trading, perhaps because a compensation is required for liquidity providers, we expect the excess in the price increase to disappear over the next few periods. Consequently, we measure the permanent effect of the intensive trading by the cumulative abnormal return from the end of the period immediately preceding the intensive trading to 10 periods after the intensive trading period, $\mathrm{CAR}(0,+10)$. If stock prices adjust completely to the new information over the 10 periods following the intensive trading period, the cumulative abnormal return from interval +1 to interval $+10, \mathrm{CAR}(+1,+10)$, corresponds to the transitory part of the return associated with the intensive trading period, which we call the temporary price effect following Holthausen, Mayers, and Leftwich (1987). Panel A of Table 4 shows that the permanent effect of the intensive buying by foreign investors is $0.897 \%$ in contrast to the temporary effect which is a significantly negative $-0.144 \%$. The temporary effect can be viewed as compensation to liquidity providers.

When we turn to intensive selling intervals, we find that intensive selling periods follow positive mean-adjusted returns. The cumulative mean-adjusted return from D-10 to D-1 is $0.137 \%$, in contrast to $0.314 \%$ for intensive buying intervals. The mean-adjusted return at D0 is $-0.730 \%$. The permanent effect is only $-0.136 \%$ with a $t$-statistic of -2.97 . In contrast, the temporary effect is $0.594 \%$ with a $t$-statistic of 13.37. The permanent effect of sales is therefore minimal and most of the price decline during the period 
of intensive selling reverses over the subsequent periods, and thus can be regarded as a compensation for liquidity providers.

We now compare the price impact of intensive trading by foreign investors to the price impact of intensive trading by domestic institutions. Panel B of Table 4 shows that purchases by domestic institutions follow insignificant cumulative mean-adjusted returns in contrast to purchases by foreign investors. Purchases by domestic institutions have a higher price impact than purchases by foreign investors. The D0 mean-adjusted return for institutions is $1.220 \%$ which is $0.179 \%$ more than for foreign investors. The permanent impact is $0.950 \%$, which exceeds the price impact of trades by foreign investors by $0.053 \%$. Looking at sell trades by domestic institutions, we find that institutions sell after positive returns. The average cumulative mean-adjusted return before the period of intensive selling is $0.415 \%$, which is substantially larger than for intensive selling by foreign investors. Their price impact at D0 is higher in absolute value since it is $-0.933 \%$ compared to $-0.730 \%$ for foreign investors, but the permanent impact is actually less for domestic institutions since it is $-0.085 \%$ compared to $-0.136 \%$ for foreign institutions. Based on this evidence, we have to conclude that the differences in price impact for sell trades between domestic and foreign institutional investors are small.

Panel $\mathrm{C}$ of Table 4 provides evidence for domestic individual investors. Domestic individual investors buy intensively after intervals of negative returns. We see that the immediate price impact of their buy trades is similar to the one of domestic institutions, but the permanent price impact is higher. Domestic individuals sell after intervals of positive returns. The immediate price impact of their sell trades is comparable to the one of domestic institutions, but the permanent price impact is higher also. For individual trades, the permanent price impact for sell trades is $-0.456 \%$, while for domestic institutions it is $-0.085 \%$. In other words, the permanent price impact of individual investors is consistent with them being better informed than either domestic or foreign institutions. Though not reported, it is striking that the relative size of the price-setting imbalances of domestic institutions and foreign investors in our 
sample of intensive trading periods are roughly of the same size. For instance, the price-setting buy imbalance of foreign investors at D0 is $20.72 \%$ relative to the total trade volume of the day, while the price-setting buy imbalance of domestic institutions is $20.27 \%$. In contrast, the price-setting buy imbalance of individuals is a much smaller $6.28 \%$. In other words, individuals have a large permanent price impact for trades that are less than a third the size of the trades of domestic or foreign institutions.

\subsection{The determinants of the returns around periods of intensive trading by investor types}

A concern with our results is that they could be driven by differences in firm characteristics and market conditions. To control for these difference, we regress the estimated CARs on dummies for investor groups and the variables we used in the regressions reported in the previous section. In Panel A of Table 5, we show regressions for the permanent price impact of periods of intensive trading. The message of the regressions is clearer for periods of intensive selling than for periods of intensive buying. For periods of intensive selling, the price impact is largest for individual investors and is not significantly different for domestic institutions and foreign investors. For periods of intensive buying, the price impact is largest for individuals in the first regression, but as we add control variables the price impact increases for domestic institutions and foreign investors so that with all the control variables the permanent price impact is higher for domestic institutions and foreign investors than for domestic individuals. We provide the same regressions for the temporary price impact in Panel B. The highest temporary price impact in absolute value is for domestic institutions. Foreign investors have less of an impact than domestic institutions. For sales only, they seem to have more of an impact than domestic individuals. Finally, we provide regressions for CAR(-10, -1) in Panel C. For these regressions, foreign investors have a higher cumulative abnormal return before the period of intensive buying than either domestic institutions or domestic individuals; the opposite occurs before periods of intensive selling. 
These regressions indicate that there is no evidence that foreign investors' periods of intensive trading have a higher permanent price impact during a day. There is therefore no indication that the market infers from their trades that they are somehow better informed. There is no indication either that they are more impatient than domestic institutions in the sense of being willing to pay more for immediate execution, in that the temporary impact of their periods of intensive trading is never less than the temporary impact of periods of intensive trading of domestic institutions. The key difference between domestic and foreign investors when they trade intensively has nothing to do with what happens to prices during the interval when investors trade intensively or afterwards. Instead, it has to do with what happens before they trade intensively. As Figure 3 makes clear, prices move more against the trades of foreign investors before they trade intensively than they do against the trades of domestic investors. This could be because the trading of foreign investors is more anticipated or because of intra-day return chasing by foreigners. In order to see whether foreign trading is more anticipated, we regress the CAR $(0,+1)$ on $\operatorname{CAR}(-10,-1)$, allowing for a different coefficient for foreign investors. Greater anticipation means that the market is less surprised by the intensive trading taking place. For purchases (sales), this means that a higher (lower) CAR(-10,-1) is associated with a lower (higher) $\operatorname{CAR}(0,+1)$. This implies that there should be a negative coefficient on CAR $(-10,-1)$. We find that the coefficient is negative for each type of investor. More importantly, we find no evidence that it is greater in absolute value for foreign investors, so that there is no evidence that periods of intensive trading by foreign investors are more anticipated than periods of intensive trading by domestic investors.

The result that prices move against foreign investors before they trade intensively suggests that they use price information differently from domestic institutions. Comparing the large buy trades of foreign investors to those of domestic institutions, we find (in results not reported in a table) that the return from the previous close is $0.762 \%$ when foreign investors buy and $0.427 \%$ when domestic institutions buy. Before large sell trades, the return is $0.159 \%$ when foreign investors sell and $0.458 \%$ when domestic 
institutions sell. This is consistent with foreign institutions trading more on intra-day momentum than domestic institutions. If we make the same comparison with domestic individual investors, we find no difference for buy trades but the return before large sell trades for these investors is $0.662 \%$, which is much larger than the return before large sell trades for foreign investors.

Another way to understand better why foreign investors perform poorly compared to domestic investors when they trade intensively is provided by Table 6 . To construct the table, we split the stocks each day into quintiles based on differences in trade values between domestic and foreign investors (normalized by the total trade value of the stock for the day), and report the results using a sample of large trades over 50 million won. The table delivers two consistent messages. First, foreign investors are disadvantaged when they have high trade values compared to domestic investors, but domestic investors are not equally disadvantaged when they have high trade values compared to foreign investors. For instance, for the comparison of buy trades for domestic institutions and foreign investors, the quintile where foreign investors have the highest trade value compared to domestic institutions (quintile Q1) shows the price ratio difference of $-0.379 \%$. In contrast, it is still negative and $-0.040 \%$ for the quintile where domestic institutions have the highest trade value compared to foreign investors (quintile Q5). Second, when foreign investors have a high trade value relative to a type of domestic investors, prices move more in the direction of the trade value of foreign investors than when domestic investors have a high trade value. Looking again at buy trades, we see that when foreign investors have a high trade value compared to domestic institutions, the average daily return is $0.986 \%$. The average return is significantly lower when domestic institutions have a high trade value compared to foreign investors. There is no evidence that the differences in daily returns are reversed on the next day. The two messages of the table are therefore that foreign investors are at a disadvantage and that prices move more in the direction of the trades of foreign investors than they do in the direction of the trades of domestic investors. The disadvantage of foreign investors is therefore consistent with the hypothesis that they pay a price for a 
trading style that differs from the trading style of domestic institutions. At the same time, however, the trading style does not seem to explain the whole difference in price ratios since the regressions of Table 3 control for the open-to-close returns which would be correlated with intra-day momentum trading and find despite this control that the price difference is worse for medium and large trades and is worse when foreigners trade intensively.

\section{Conclusion}

In this paper, we examine whether foreign investors pay more than domestic investors when they buy shares and receive less when they sell shares. We find that they do so controlling for firm characteristics and market conditions, and more so compared to domestic institutions than to domestic individual investors and only for medium and large trades. The roundtrip difference is of the order of 37 basis points when we compared foreign money managers to domestic money managers. As discussed in the introduction, the roundtrip difference is roughly equivalent to half of the difference in Jensen's monthly alpha between the top and bottom decile of mutual funds in the U.S. from 1962 through 1993. We examine whether this difference can be traced to greater impatience of foreign investors through an analysis of the price impact of intensive five-minute trading periods. We find that greater impatience cannot account for the disadvantage of foreign investors relative to domestic institutions. We also find no evidence that foreign investors are better informed. The critical difference between foreign investors and domestic investors is that prices tend to move more against foreign investors before they trade intensively. This difference is consistent with foreign investors trading more on intra-day momentum signals than domestic investors and paying a price for doing so. In the literature, some models show that it is optimal for less well-informed investors to chase returns. ${ }^{7}$ It is therefore possible that the disadvantage of foreign

\footnotetext{
${ }^{7}$ See, for instance, Wang (1993) and Brennan and Cao (1997)
} 
investors we document might be the result of them acting optimally in response to an information disadvantage. 


\section{References}

Brennan, M. J., and H. Cao, 1997, “International Portfolio Flows,” Journal of Finance, 52, 1851-1880.

Carhart, M.M., 1997, “On Persistence in Mutual Fund Performance,” Journal of Finance, 52, 57-83.

Choe, H., B.-C. Kho, and R.M. Stulz, 1999, "Do Foreign Investors Destabilize Stock Markets? The Korean experience in 1997," Journal of Financial Economics, 54, 227-264.

Coval, J.D., and T.J. Moskowitz, 1999, "Home Bias at Home: Domestic Equity Preference in Domestic Portfolios," Journal of Finance, 54, 2045-2073.

Dvorak, T., 2002, "Do Domestic Investors Have an Informational Advantage? Evidence from Indonesia," working paper, Williams College.

Froot, K., P. O'Connell, and M. Seasholes, 2001, “The Portfolio Flows of International Investors," Journal of Financial Economics, 59, 151-193.

Froot, K.A., and T. Ramadorai, 2001, “The Information Content of International Portfolio Flows,” NBER working paper 8472, National Bureau of Economic Research.

Grinblatt, M., and M. Keloharju, 2000, “The Investment Behavior and Performance of Various Investor Types: A Study of Finland's Unique Data Set," Journal of Financial Economics, 55, 43-67.

Hau, H., 2001, "Location Matters: An Examination of Trading Profits," Journal of Finance, 56, 19591983.

Holthausen, R.W., R.W. Leftwich, and D. Mayers, 1987, "The Effect of Large Block Transactions on Security Prices: A Cross-Sectional Analysis,” Journal of Financial Economics, 19, 237-267.

Kang, J.-K., and R.M. Stulz, 1997, "Why is There a Home Bias? An Analysis of Foreign Portfolio Equity Ownership in Japan," Journal of Financial Economics, 46, 2-28.

Keim, D., 2003, "The Cost of Trend Chasing and the Illusion of Momentum Profits," working paper, Wharton School, University of Pennsylvania. 
Lee, C.M. C., and M.A. Ready, 1991, "Inferring Trade Direction from Intraday Data," Journal of Finance, $46,733-746$.

Seasholes, M., 2000, "Smart Foreign Traders in Emerging Markets," working paper, Harvard Business School.

Shukla, R. K., and G. B. van Inwegen, 1995, "Do Domestics Perform Better than Foreigners? An Analysis of UK and US Mutual Fund Managers," Journal of Economics and Business, 47, 241-254.

Tesar, L.L., and I.M. Werner, 1995, "Home Bias and High Turnover," Journal of International Money and Finance, 14, 467-492.

Wang, J., 1993, “A Model of Intertemporal Asset Prices under Asymmetric Information,” Review of Economic Studies, 6, 249-282. 


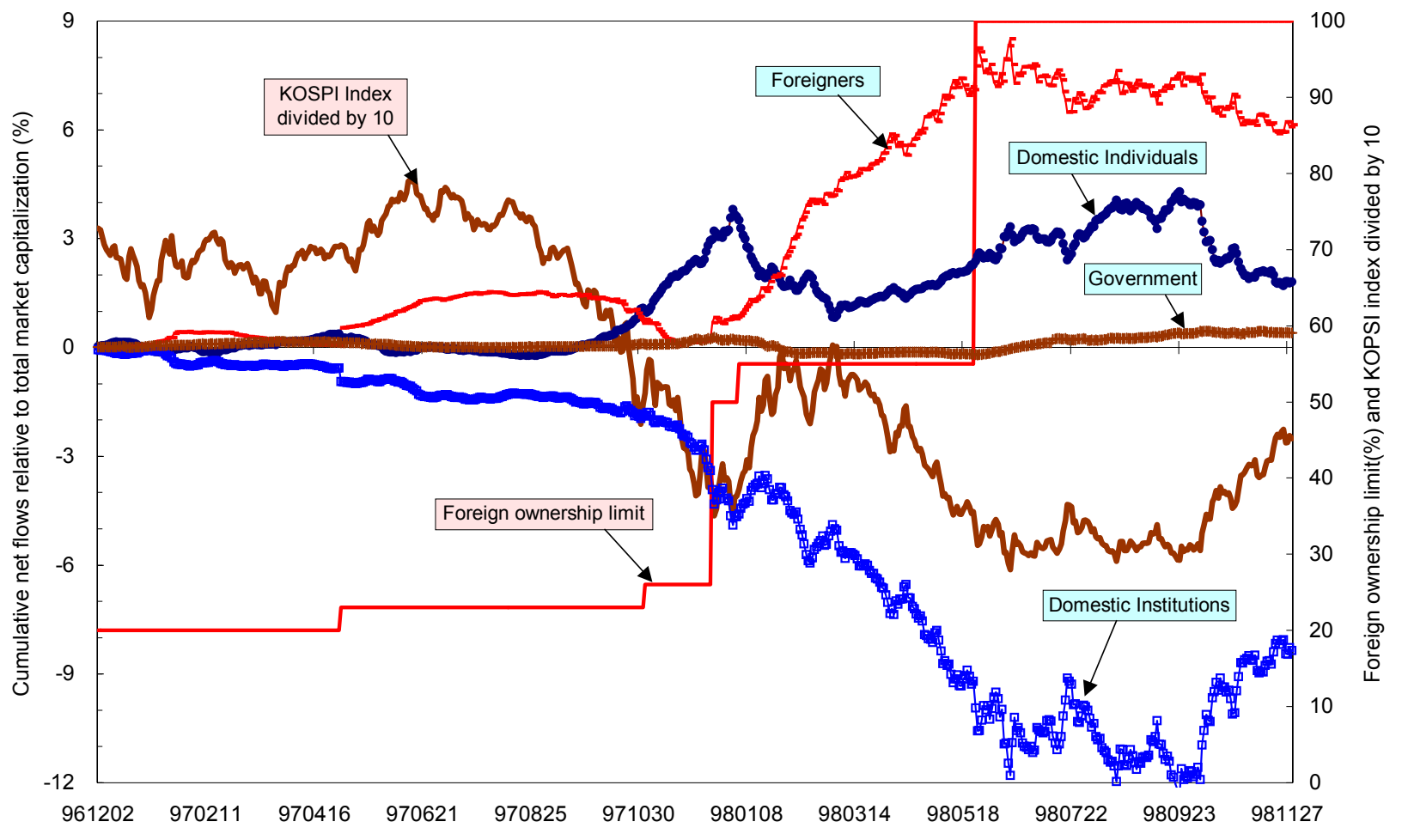

Figure 1

Cumulative net flows relative to total market capitalization for various investor groups (\%, left axis), foreign ownership limit (\%, right axis), and KOSPI index divided by 10 (right axis). 




\section{Figure 2}

Time series plot of daily trade-value-weighted average differences in buy (sell) price ratios across different investors

The average buy (sell) price ratio for a stock is computed as $\left(B_{i, j}^{d} / A_{i}^{d}\right) \times 100(\%)$, where $B_{i, j}^{d}=\Sigma_{t} P_{i, j}^{d t} V_{i, j}^{d t} / \Sigma_{t} V_{i, j}^{d t}$ is the volumeweighted average buy (sell) price for investor type $j\left(j=(1), \ldots\right.$, (3)) for stock $i$ on day $d$, and $A_{i}^{d}=\Sigma_{t} P_{i}^{d t} V_{i}^{d t} / \Sigma_{t} V_{i}^{d t}$ is the volumeweighted average price for all trades for stock $i$ on day $d$. Split trades originated from an order are aggregated into a trade. Stocks whose prices have fallen below 1,000 won during the sample period are excluded from the analysis, and the analysis was performed on the stock-days with at least one foreign trade. The daily aggregate trade values for each investor type are used as weights in averaging price ratios across stocks on a day. The plot shows differences in the average daily price ratios across investor types. It also shows how the KOSPI index, won/US\$ exchange rate, and the ownership limits evolved during the sample period. 


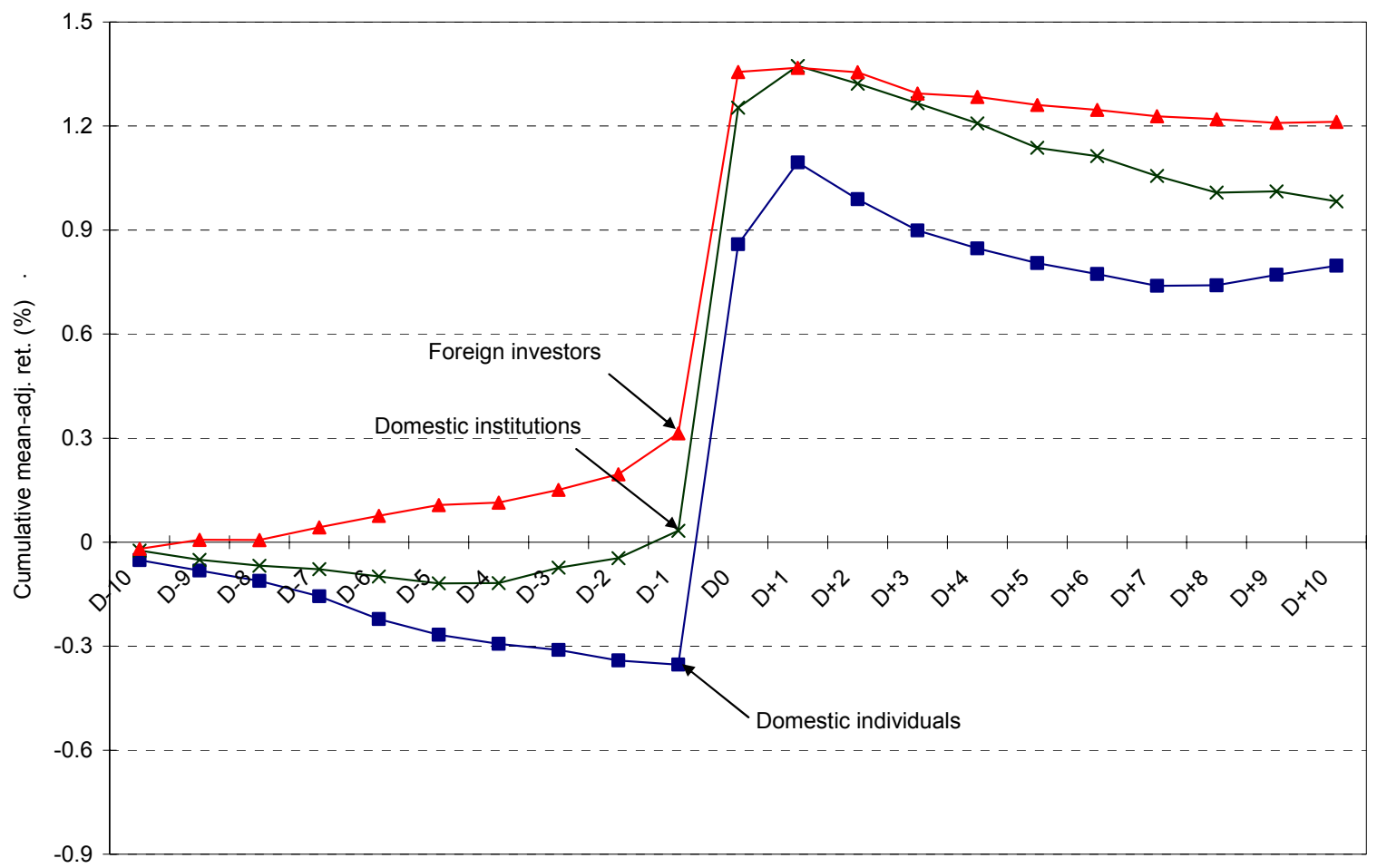

Five-minute invervals around the event of large purchases

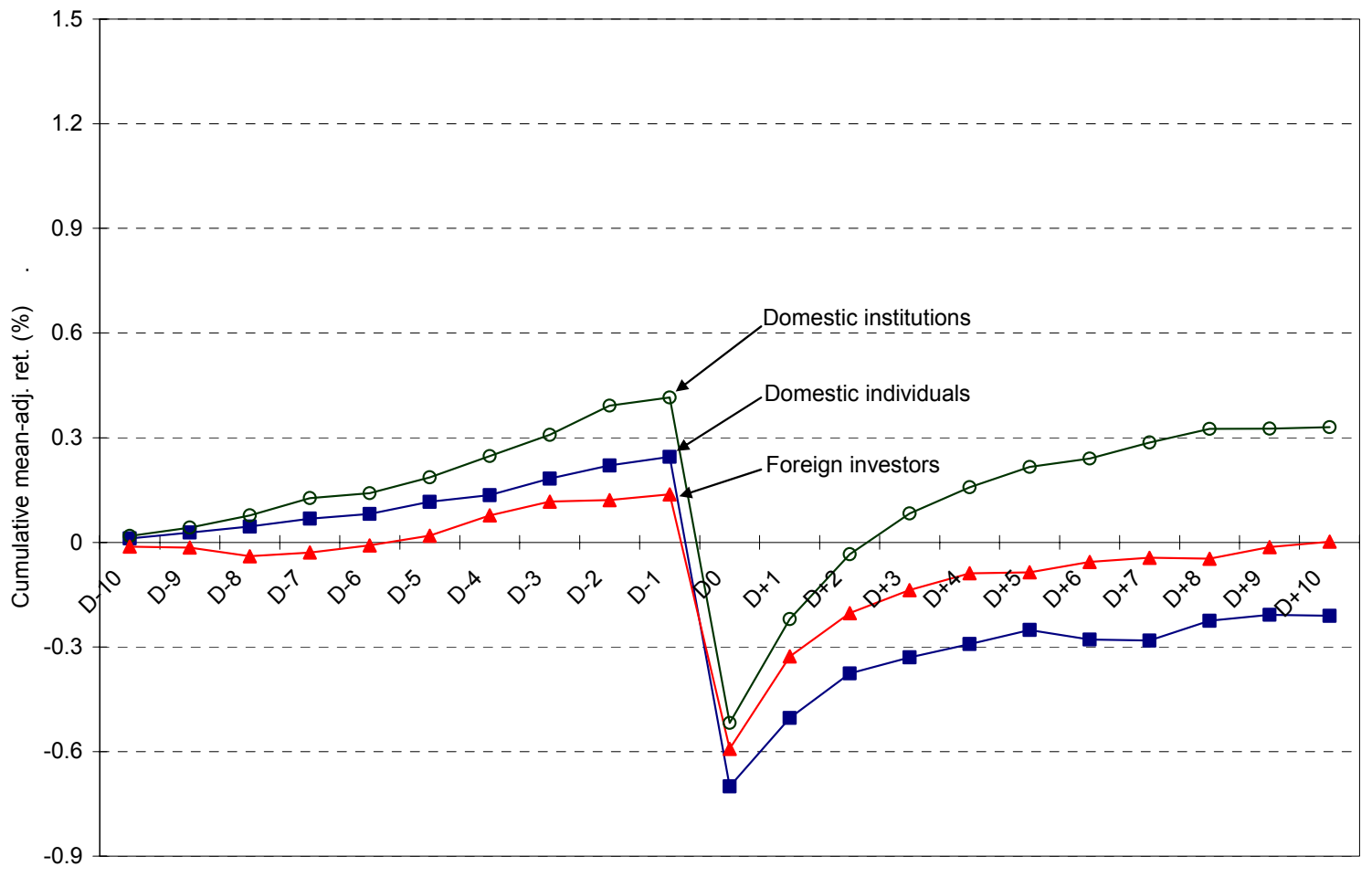

Five-minute Intervals around the event of large sales 
Figure 3

Cumulative mean-adjusted return (\%) around 5-minute intervals of large price-setting trades

The price-setting order-imbalance (price-setting buy minus price-setting sell volume in shares) attributable to each type of investors (foreign investors, domestic institutions, individuals) is calculated for each eligible stock listed at the KSE from Dec. 2, 1996 to Nov. 30 , 1998, and then is normalized by the total share volume for the stock on the day. The sample includes the ten intervals with the largest normalized price-setting net buy and net sell order-imbalances for each investor type for each stock, excluding those intervals with less than 1,000 shares. The mean-adjusted return is computed for each interval as the interval return for the stock minus the mean observed on the same day of the week and the same time interval over the sample period. The figure shows the cumulative mean-adjusted return from the 10th interval before an interval selected for the sample to the 10th interval afterwards for each investor type for purchases and for sales. 
Table 1

Average proportion (\%) of intraday trading volume for each type of investor

\begin{tabular}{|c|c|c|c|c|c|c|c|c|c|c|c|c|}
\hline \multirow{3}{*}{ Trading intervals } & \multicolumn{6}{|c|}{ Relative to the trading volume for the interval } & \multicolumn{6}{|c|}{ Relative to the trading volume for the day } \\
\hline & \multicolumn{3}{|c|}{ (in values) } & \multicolumn{3}{|c|}{ (in shares) } & \multicolumn{3}{|c|}{ (in values) } & \multicolumn{3}{|c|}{ (in shares) } \\
\hline & (1) & (2) & (3) & (1) & (2) & (3) & (1) & (2) & (3) & (1) & (2) & (3) \\
\hline Morning opening batch & 75.0 & 12.4 & 12.7 & 81.8 & 8.8 & 9.4 & 2.9 & 0.7 & 0.7 & 3.9 & 0.5 & 0.5 \\
\hline $9: 30-10: 30$ & 71.4 & 17.0 & 11.6 & 76.9 & 13.7 & 9.5 & 18.8 & 4.5 & 3.0 & 20.6 & 3.6 & 2.4 \\
\hline $10: 30-11: 30$ & 68.8 & 17.2 & 14.0 & 74.3 & 14.2 & 11.5 & 15.8 & 3.9 & 3.1 & 17.0 & 3.2 & 2.6 \\
\hline Afternoon opening batch & 70.1 & 12.8 & 17.1 & 77.8 & 9.2 & 13.0 & 1.4 & 0.3 & 0.4 & 1.9 & 0.2 & 0.3 \\
\hline $13: 00-14: 00$ & 65.2 & 17.9 & 16.9 & 71.6 & 14.6 & 13.8 & 10.5 & 3.0 & 2.8 & 11.6 & 2.4 & 2.2 \\
\hline $14: 00-14: 50$ & 65.6 & 18.0 & 16.5 & 71.5 & 14.8 & 13.7 & 11.6 & 3.2 & 3.0 & 12.4 & 2.6 & 2.4 \\
\hline Closing batch & 62.2 & 18.7 & 19.1 & 67.8 & 15.9 & 16.3 & 4.4 & 1.4 & 1.4 & 4.5 & 1.1 & 1.1 \\
\hline Extended trading hours & 60.4 & 20.5 & 19.1 & 65.4 & 17.3 & 17.3 & 0.2 & 0.4 & 0.2 & 0.2 & 0.2 & 0.3 \\
\hline
\end{tabular}

This table reports the average proportions (\%) of intraday trading volume for each of three classes of investors relative to the total trading volume for the interval and for the day (both in shares and values, respectively), using a sample of stocks whose prices have not fallen below 1,000 won during the sample period from Dec. 2, 1996 to Nov. 30, 1998, and whose stock-days have at least one foreign trade. The three classes of investors include (1) Korean individuals (2) Korean money managers (securities, mutual, pension funds) and banks (banks, insurance, merchant banks), and (3) Foreign money managers and banks (including resident foreigners). 
Table 2

Average buy (sell) price ratios for 6 investor types relative to the average trading price (12/2/96 11/30/98: 586 days)

Panel A. Equal-weighted average buy price ratios relative to daily average prices (\%)

\begin{tabular}{|c|c|c|c|c|c|c|}
\hline \multirow[b]{2}{*}{ Buy price ratios } & \multicolumn{3}{|c|}{ Domestic investors } & \multicolumn{3}{|c|}{ Non-resident foreign investors } \\
\hline & $\begin{array}{c}(1) \\
\text { Individual } \\
\end{array}$ & $\begin{array}{l}\text { (2) Money } \\
\text { managers }\end{array}$ & $\begin{array}{c}\text { (3) } \\
\text { Banks }\end{array}$ & $\begin{array}{c}(4) \\
\text { Individual } \\
\end{array}$ & $\begin{array}{l}\text { (5) Money } \\
\text { managers }\end{array}$ & $\begin{array}{c}\text { (6) } \\
\text { Banks }\end{array}$ \\
\hline \multicolumn{7}{|l|}{ Buy: All trades } \\
\hline Avg. of daily median trade size ( 000 won) & 17,678 & 53,906 & 68,108 & 19,700 & 44,901 & 59,619 \\
\hline Avg. of mean $A$ (won) & 28,907 & 30,869 & 30,156 & 24,506 & 30,611 & 34,758 \\
\hline Avg. of mean Buy $B / A$ & 99.844 & 99.999 & 99.922 & 100.013 & 99.988 & 99.930 \\
\hline (t-stat: $\mathrm{H}_{0}=100$ ) & $(-23.34)$ & $(-0.06)$ & $(-4.12)$ & $(0.32)$ & $(-1.21)$ & $(-2.68)$ \\
\hline Avg. of std dev of Buy $B / A$ & 0.768 & 1.178 & 1.290 & 1.481 & 1.229 & 1.067 \\
\hline Avg. number of stocks per day & 73.8 & 48.5 & 20.9 & 6.7 & 68.2 & 9.7 \\
\hline Difference of Buy $B / A$ from (1) & & -0.142 & -0.031 & -0.082 & -0.151 & -0.058 \\
\hline (t-stat: $\mathrm{H}_{0}=0$ ) & & $(-9.66)$ & $(-1.36)$ & $(-1.97)$ & $(-10.50)$ & $(-1.86)$ \\
\hline Difference of Buy $B / A$ from (2) & & & 0.065 & -0.008 & 0.024 & 0.012 \\
\hline (t-stat: $\mathrm{H}_{0}=0$ ) & & & $(2.53)$ & $(-0.13)$ & $(1.54)$ & $(0.32)$ \\
\hline Difference of Buy $B / A$ from (3) & & & & -0.141 & -0.034 & -0.031 \\
\hline (t-stat: $\left.\mathrm{H}_{0}=0\right)$ & & & & $(-1.66)$ & $(-1.25)$ & $(-0.57)$ \\
\hline \multicolumn{7}{|c|}{ Buy: Small trades subsample ( $\leq 5$ million won) } \\
\hline Avg. of daily median trade size ( 000 won) & 1,916 & 2,223 & 2,526 & 2,519 & 2,574 & 2,586 \\
\hline Avg. number of stocks per day & 73.4 & 23.2 & 4.7 & 3.6 & 32.4 & 4.5 \\
\hline Difference of Buy $B / A$ from (1) & & -0.173 & -0.060 & 0.015 & -0.012 & 0.127 \\
\hline (t-stat: $\left.\mathrm{H}_{0}=0\right)$ & & $(-5.99)$ & $(-1.03)$ & $(0.24)$ & $(-0.67)$ & $(2.67)$ \\
\hline Difference of Buy $B / A$ from (2) & & & 0.190 & 0.256 & 0.130 & 0.293 \\
\hline$\left(\mathrm{t}\right.$-stat: $\left.\mathrm{H}_{0}=0\right)$ & & & $(1.67)$ & $(2.07)$ & $(3.11)$ & $(3.41)$ \\
\hline \multicolumn{7}{|c|}{ Buy: Medium trades subsample ( $\leq 50$ million won) } \\
\hline Avg. of daily median trade size ( 000 won) & 10,239 & 22,520 & 24,608 & 16,392 & 19,224 & 18,696 \\
\hline Avg. number of stocks per day & 71.1 & 37.6 & 14.5 & 4.7 & 54.8 & 7.9 \\
\hline Difference of Buy $B / A$ from (1) & & 0.016 & 0.091 & -0.099 & -0.043 & -0.044 \\
\hline (t-stat: $\mathrm{H}_{0}=0$ ) & & $(1.05)$ & $(3.49)$ & $(-1.93)$ & $(-3.21)$ & $(-1.24)$ \\
\hline Difference of Buy $B / A$ from (2) & & & 0.038 & -0.205 & -0.042 & -0.106 \\
\hline$\left(\mathrm{t}\right.$-stat: $\left.\mathrm{H}_{0}=0\right)$ & & & $(1.14)$ & $(-2.61)$ & $(-2.38)$ & $(-2.14)$ \\
\hline \multicolumn{7}{|c|}{ Buy: Large trades subsample ( $>50$ million won) } \\
\hline Avg. of daily median trade size ( 000 won) & 75,871 & 135,793 & 148,616 & 103,547 & 148,515 & 193,062 \\
\hline Avg. number of stocks per day & 31.9 & 27.5 & 11.2 & 1.8 & 27.6 & 3.8 \\
\hline Difference of Buy $B / A$ from (1) & & 0.107 & 0.110 & 0.130 & -0.016 & 0.022 \\
\hline (t-stat: $\mathrm{H}_{0}=0$ ) & & $(4.83)$ & $(3.06)$ & $(1.00)$ & $(-0.60)$ & $(0.29)$ \\
\hline Difference of Buy $B / A$ from (2) & & & -0.029 & -0.156 & -0.143 & -0.166 \\
\hline (t-stat: $\left.\mathrm{H}_{0}=0\right)$ & & & $(-0.85)$ & $(-0.88)$ & $(-5.27)$ & $(-2.22)$ \\
\hline
\end{tabular}


Table 2 (Continued)

Panel B. Equal-weighted average sell price ratios relative to daily average prices (\%)

\begin{tabular}{|c|c|c|c|c|c|c|}
\hline \multirow[b]{2}{*}{ Sell price ratios } & \multicolumn{3}{|c|}{ Domestic investors } & \multicolumn{3}{|c|}{ Non-resident foreign investors } \\
\hline & $\begin{array}{c}(1) \\
\text { Individual }\end{array}$ & $\begin{array}{l}\text { (2) Money } \\
\text { managers }\end{array}$ & $\begin{array}{c}\text { (3) } \\
\text { Banks }\end{array}$ & $\begin{array}{c}\text { (4) } \\
\text { Individual }\end{array}$ & $\begin{array}{l}\text { (5) Money } \\
\text { managers }\end{array}$ & $\begin{array}{c}(6) \\
\text { Banks }\end{array}$ \\
\hline \multicolumn{7}{|l|}{ Sell: All trades } \\
\hline Avg. of daily median trade size ( 000 won) & 17,857 & 42,000 & 64,542 & 20,635 & 41,258 & 39,268 \\
\hline Avg. of mean $A$ (won) & 26,921 & 27,482 & 27,538 & 27,565 & 27,974 & 28,879 \\
\hline Avg. of mean Sell $B / A$ & 100.129 & 99.929 & 100.065 & 99.995 & 99.961 & 99.964 \\
\hline (t-stat: $\left.\mathrm{H}_{0}=100\right)$ & $(28.14)$ & $(-6.10)$ & $(3.48)$ & $(-0.13)$ & $(-4.06)$ & $(-1.47)$ \\
\hline Avg. of std dev of Sell $B / A$ & 0.617 & 1.258 & 1.295 & 1.486 & 1.224 & 0.986 \\
\hline Avg. number of stocks per day & 72.9 & 56.6 & 23.2 & 6.0 & 66.8 & 8.8 \\
\hline Difference of Sell $B / A$ from (1) & & 0.201 & 0.062 & 0.069 & 0.175 & 0.149 \\
\hline (t-stat: $\mathrm{H}_{0}=0$ ) & & $(14.83)$ & $(3.11)$ & $(1.61)$ & $(14.47)$ & $(5.22)$ \\
\hline Difference of Sell $B / A$ from (2) & & & -0.129 & -0.015 & -0.016 & -0.050 \\
\hline (t-stat: $\left.\mathrm{H}_{0}=0\right)$ & & & $(-5.44)$ & $(-0.26)$ & $(-1.02)$ & $(-1.42)$ \\
\hline Difference of Sell $B / A$ from (3) & & & & -0.010 & 0.163 & 0.107 \\
\hline$\left(\mathrm{t}\right.$-stat: $\left.\mathrm{H}_{0}=0\right)$ & & & & $(-0.12)$ & $(6.37)$ & $(1.90)$ \\
\hline \multicolumn{7}{|c|}{ Sell: Small trades subsample ( $\leq 5$ million won) } \\
\hline Avg. of daily median trade size ( 000 won) & 1,788 & 1,358 & 2,498 & 2,357 & 2,587 & 2,561 \\
\hline Avg. number of stocks per day & 72.8 & 41.2 & 6.1 & 3.0 & 31.2 & 4.2 \\
\hline Difference of Sell $B / A$ from (1) & & 0.344 & -0.011 & 0.085 & 0.050 & 0.042 \\
\hline (t-stat: $\mathrm{H}_{0}=0$ ) & & $(17.89)$ & $(-0.24)$ & $(1.22)$ & $(3.23)$ & $(0.95)$ \\
\hline Difference of Sell $B / A$ from (2) & & & -0.350 & -0.265 & -0.218 & -0.164 \\
\hline (t-stat: $\left.\mathrm{H}_{0}=0\right)$ & & & $(-4.88)$ & $(-2.18)$ & $(-8.08)$ & $(-2.58)$ \\
\hline \multicolumn{7}{|c|}{ Sell: Medium trades subsample ( $\leq 50$ million won) } \\
\hline Avg. of daily median trade size ( 000 won) & 10,055 & 21,504 & 24,071 & 17,054 & 19,085 & 18,468 \\
\hline Avg. number of stocks per day & 71.2 & 41.4 & 16.8 & 4.1 & 53.6 & 7.0 \\
\hline Difference of Sell $B / A$ from (1) & & 0.092 & -0.015 & 0.057 & 0.131 & 0.186 \\
\hline (t-stat: $\mathrm{H}_{0}=0$ ) & & $(6.39)$ & $(-0.61)$ & $(1.10)$ & $(10.91)$ & $(5.44)$ \\
\hline Difference of Sell $B / A$ from (2) & & & -0.117 & 0.020 & 0.085 & 0.058 \\
\hline (t-stat: $\left.\mathrm{H}_{0}=0\right)$ & & & $(-3.61)$ & $(0.29)$ & $(4.67)$ & $(1.35)$ \\
\hline \multicolumn{7}{|c|}{ Sell: Large trades subsample ( $>50$ million won) } \\
\hline Avg. of daily median trade size ( 000 won) & 78,983 & 136,191 & 142,704 & 118,556 & 132,927 & 153,977 \\
\hline Avg. number of stocks per day & 31.1 & 28.6 & 12.3 & 1.8 & 25.9 & 3.1 \\
\hline Difference of Sell $B / A$ from (1) & & 0.124 & 0.030 & -0.093 & 0.241 & 0.143 \\
\hline$\left(\mathrm{t}\right.$-stat: $\left.\mathrm{H}_{0}=0\right)$ & & $(6.12)$ & $(0.95)$ & $(-0.60)$ & $(9.18)$ & $(2.46)$ \\
\hline Difference of Sell $B / A$ from (2) & & & -0.075 & -0.032 & 0.133 & 0.023 \\
\hline (t-stat: $\left.\mathrm{H}_{0}=0\right)$ & & & $(-2.36)$ & $(-0.24)$ & $(5.27)$ & $(0.36)$ \\
\hline
\end{tabular}


Table 2 (Continued)

Panel C. Trade value-weighted average buy and sell price ratios relative to daily average prices (\%)

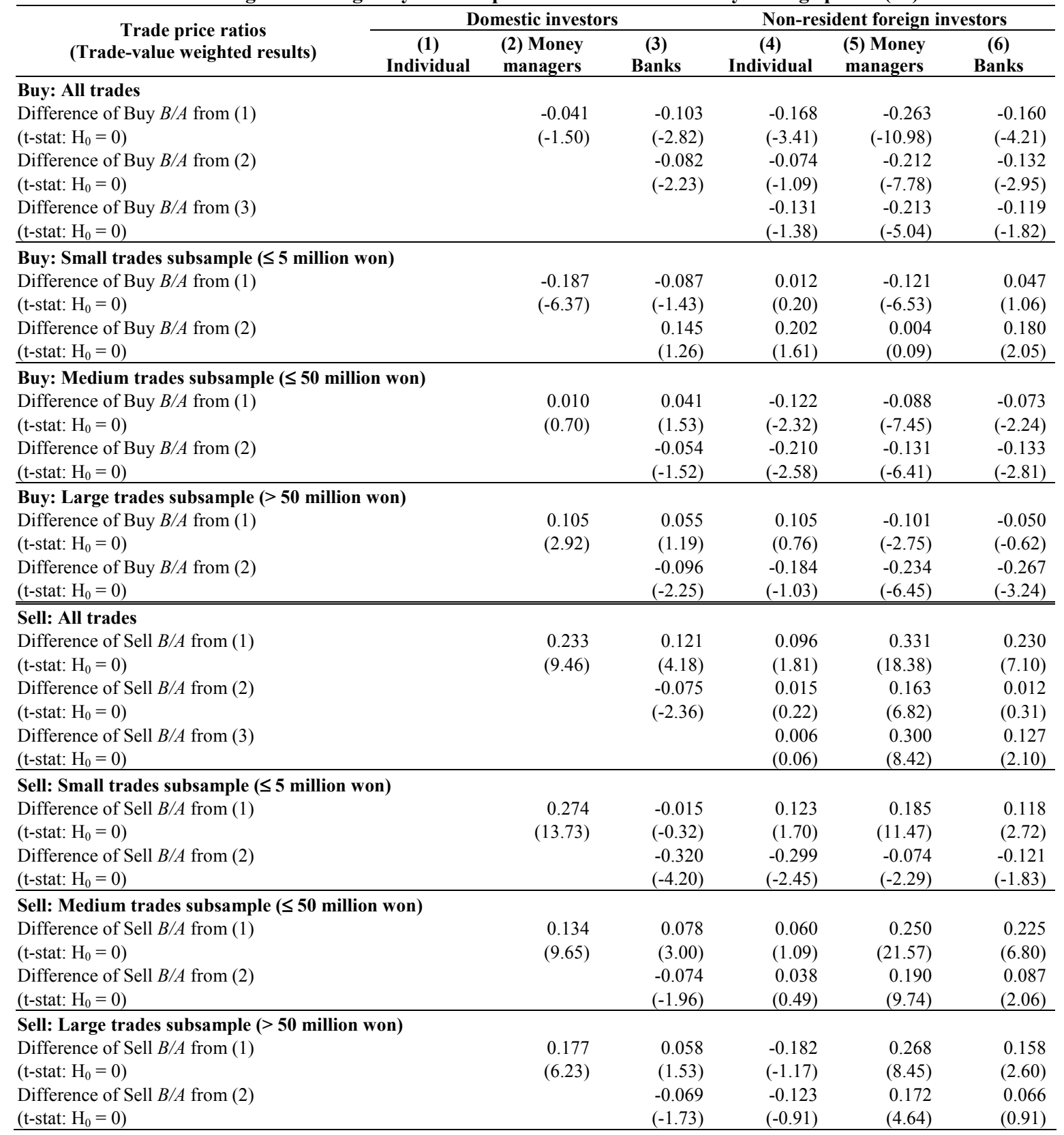

The average buy (sell) price ratio is computed as $\left(B_{i, j}^{d} / A_{i}^{d}\right) \times 100(\%)$, where $B_{i, j}^{d}=\sum_{t} P_{i, j}^{d t} V_{i, j}^{d t} / \sum_{t} V_{i, j}^{d t}$ is the volume-weighted average buy (sell) price for investor type $j(j=(1), \ldots,(6))$ for stock $i$ on day $d$, and $A_{i}^{d}=\Sigma_{t} P_{i}^{d t} V_{i}^{d t} / \Sigma_{t} V_{i}^{d t}$ is the volume-weighted average price for all trades for stock $i$ on day $d$. In order to control for a trade-volume effect on the price ratios, $B_{i, j}^{d}$ is further disaggregated into three groups based on trade sizes whose cutoff points are 5 million won and 50 million won. Split trades originated from an order are aggregated into a trade. Stocks whose prices have fallen below 1,000 won during the sample period are excluded from the analysis, and the analysis was performed on the stock-days with at least one foreign trade. For panels $\mathrm{A}$ and $\mathrm{B}$, the price ratios and their differences across investors are averaged equally across stocks on a day and then across days. For panel C, daily aggregate trade values for each investor type are used as weights in averaging price ratios across stocks on a day and then across days. T-statistics are presented in parentheses. 


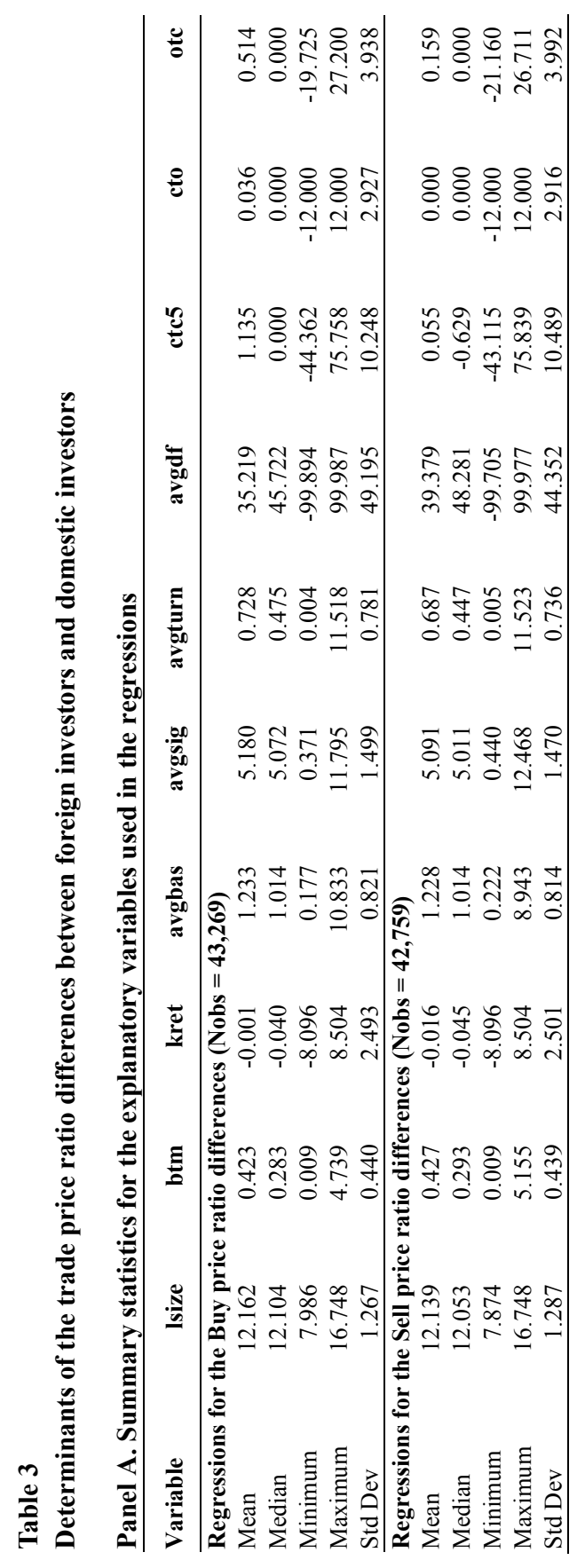




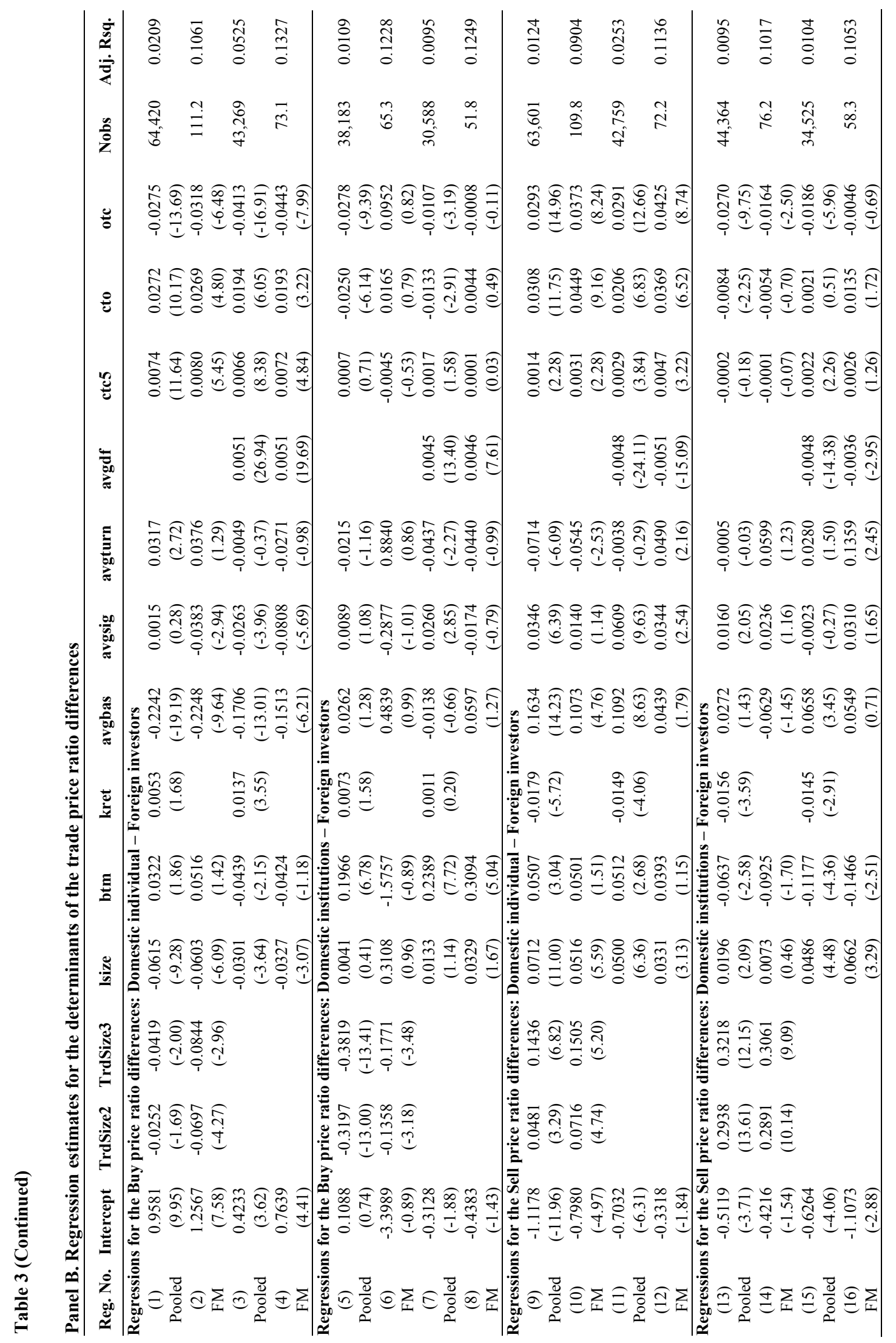




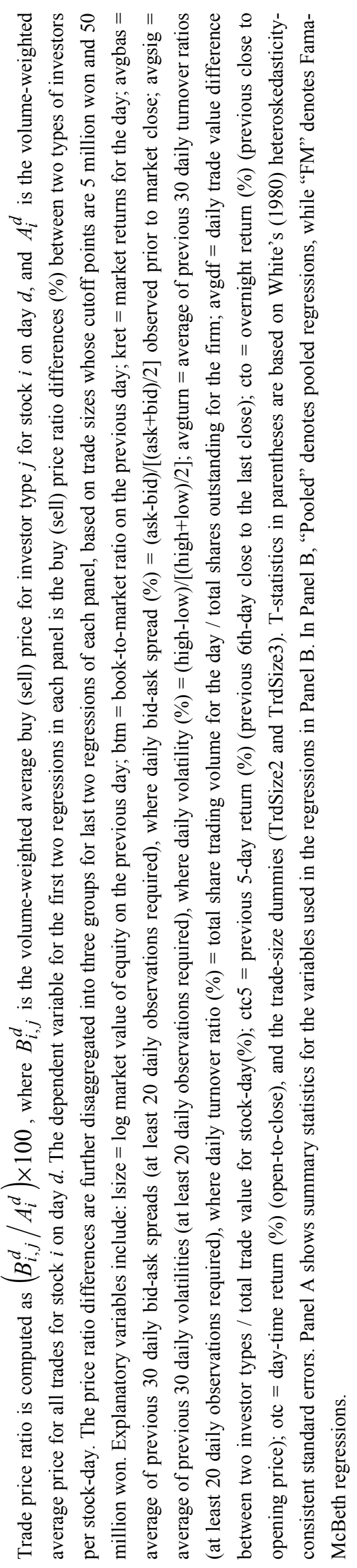




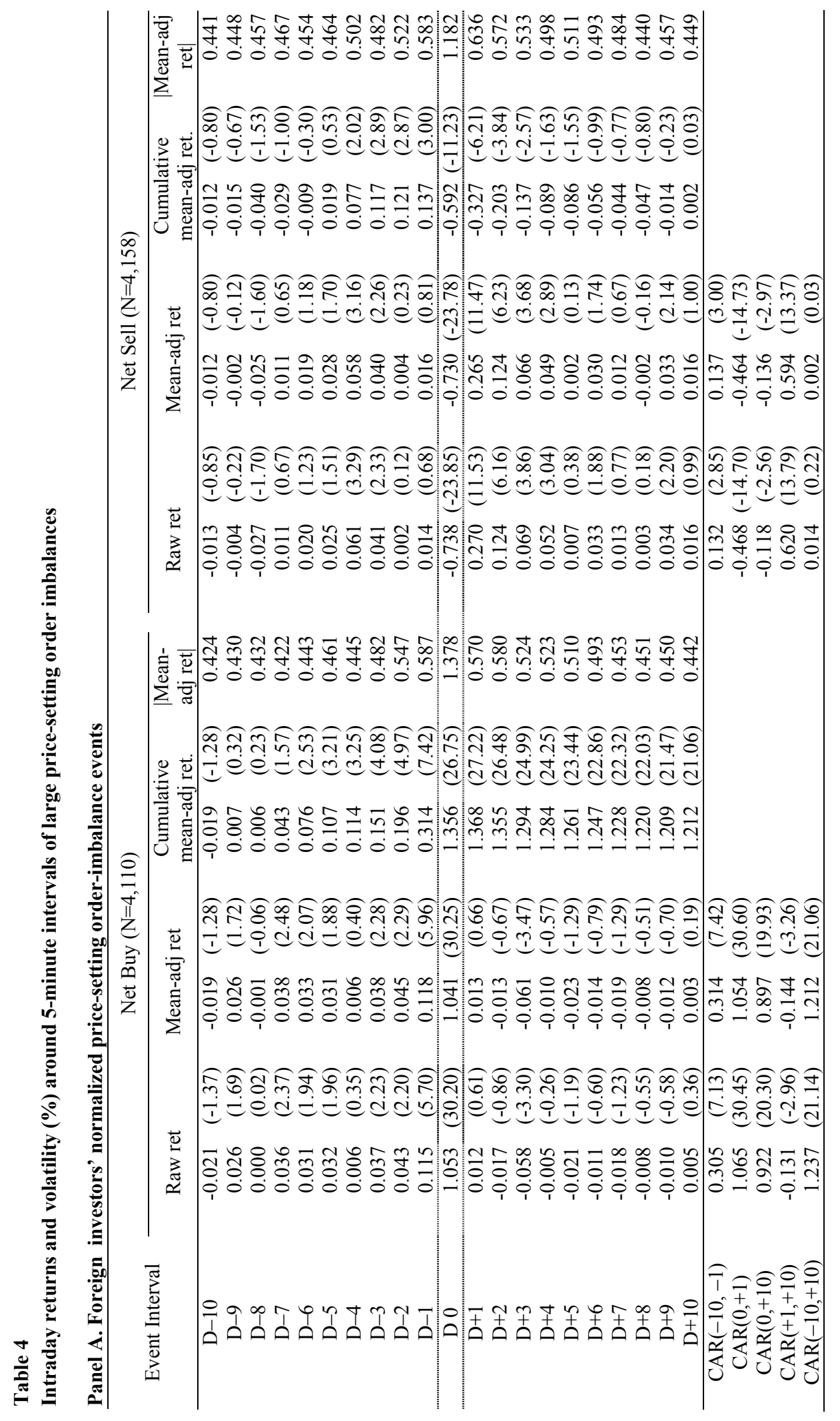




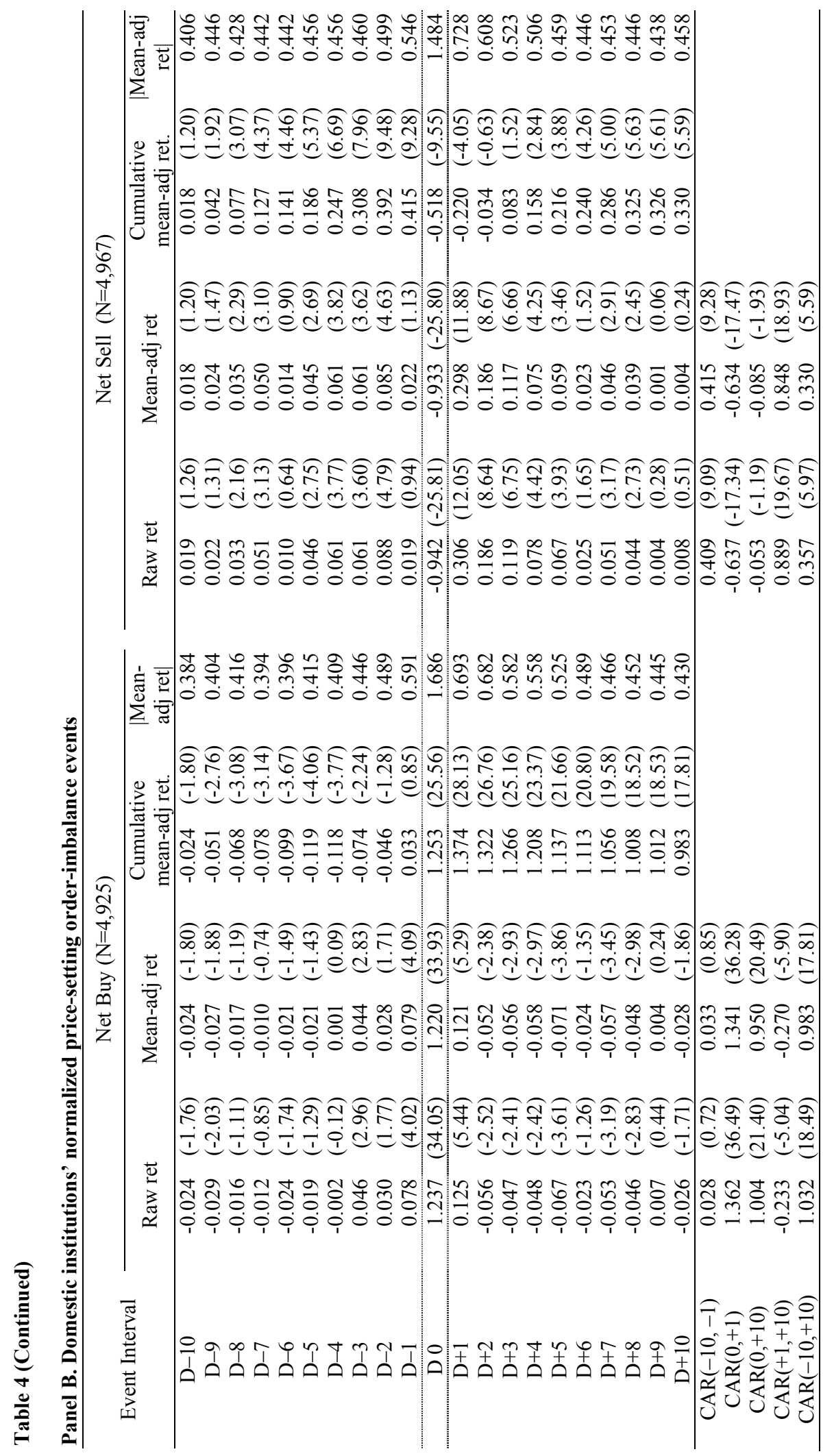




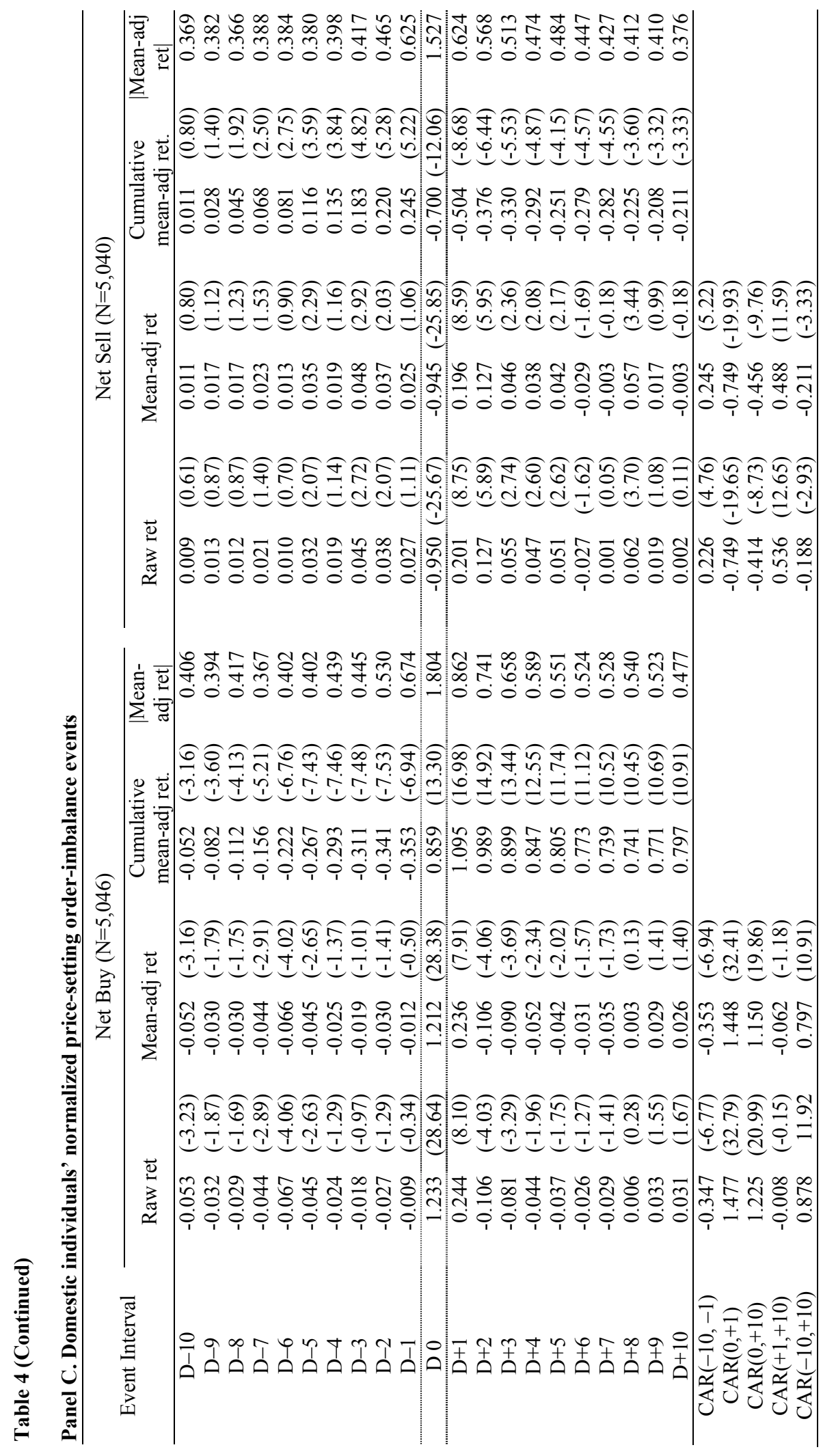

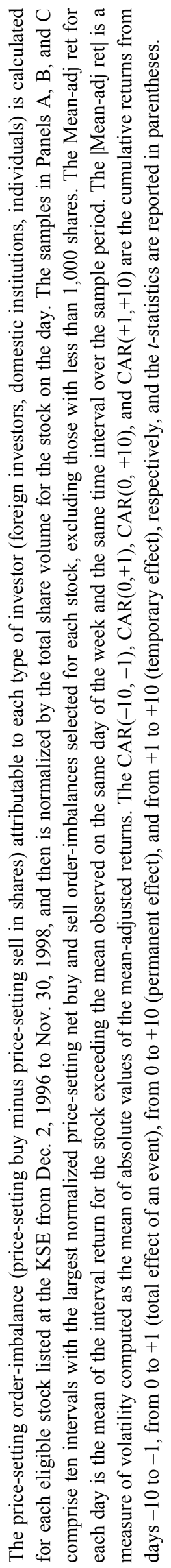




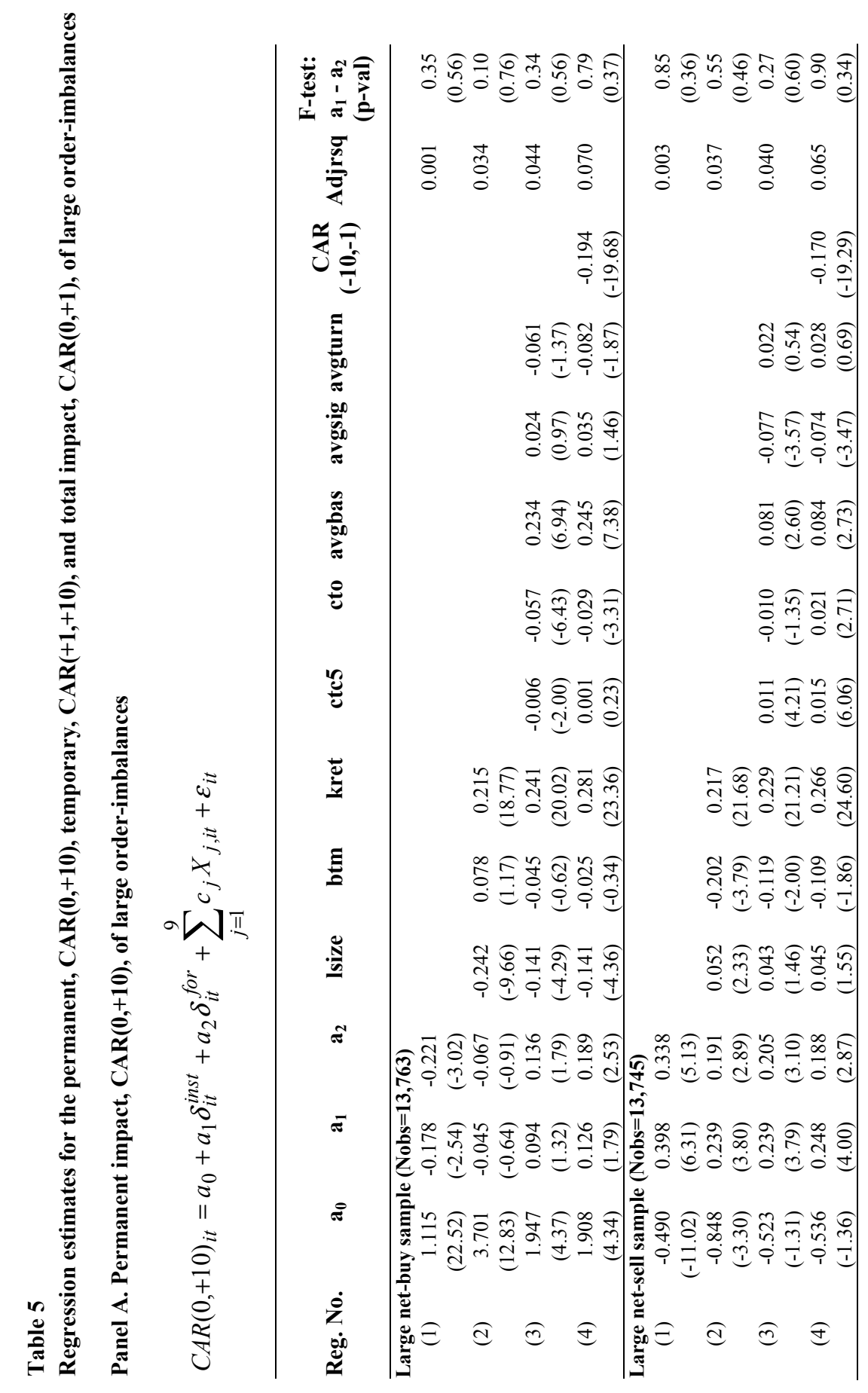




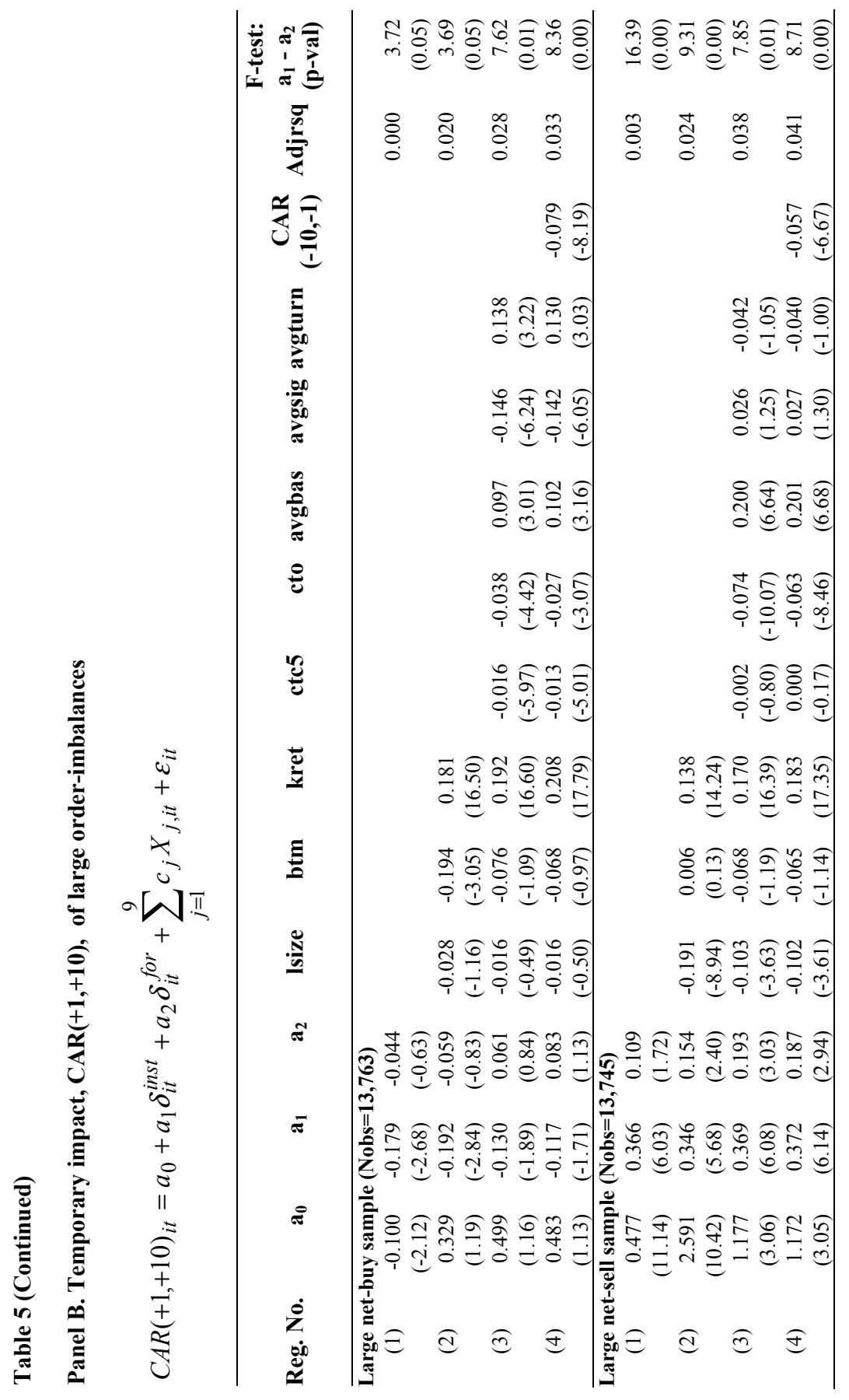



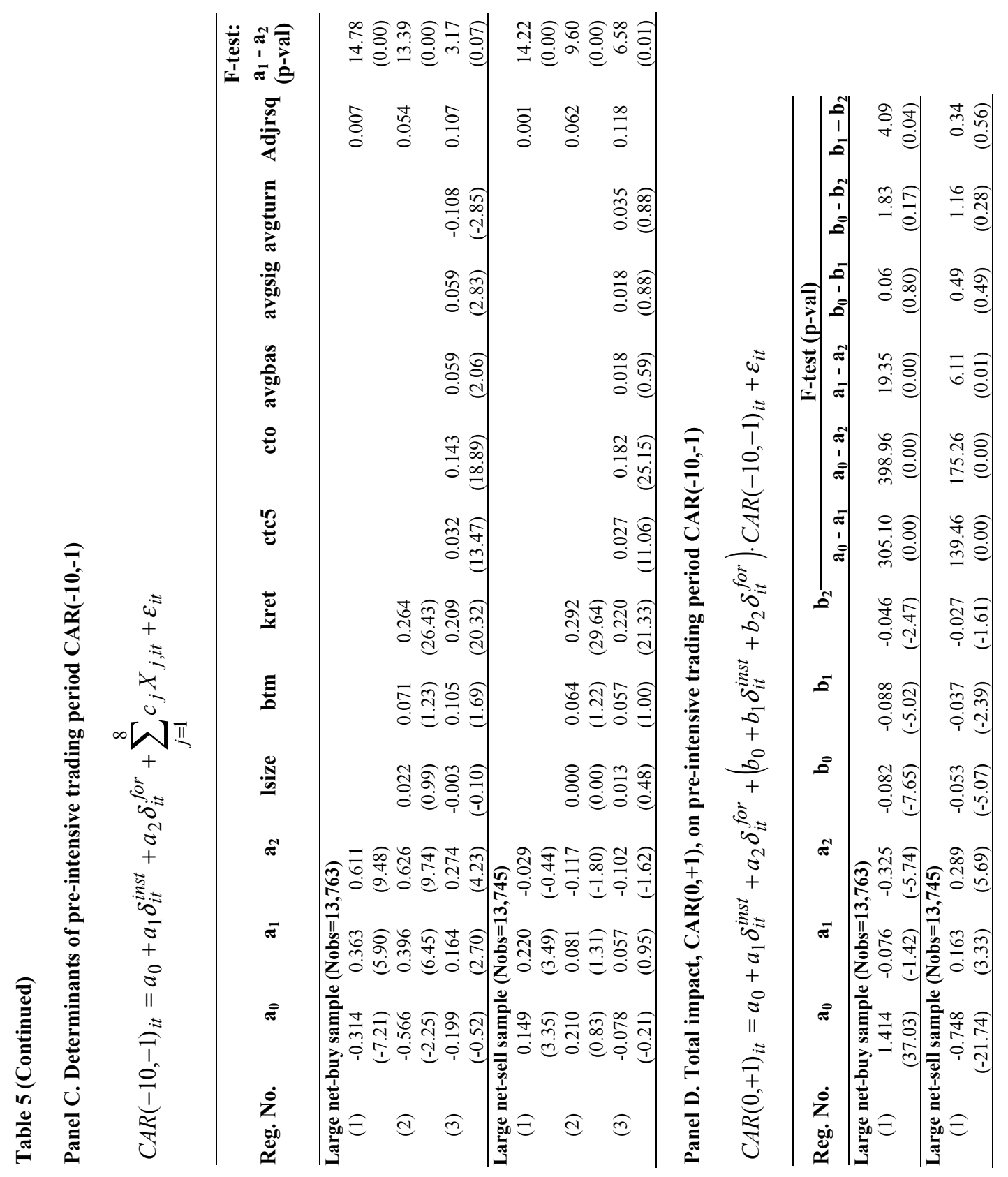


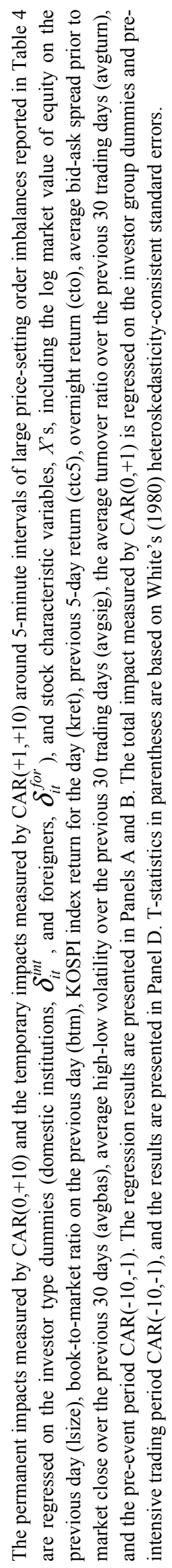




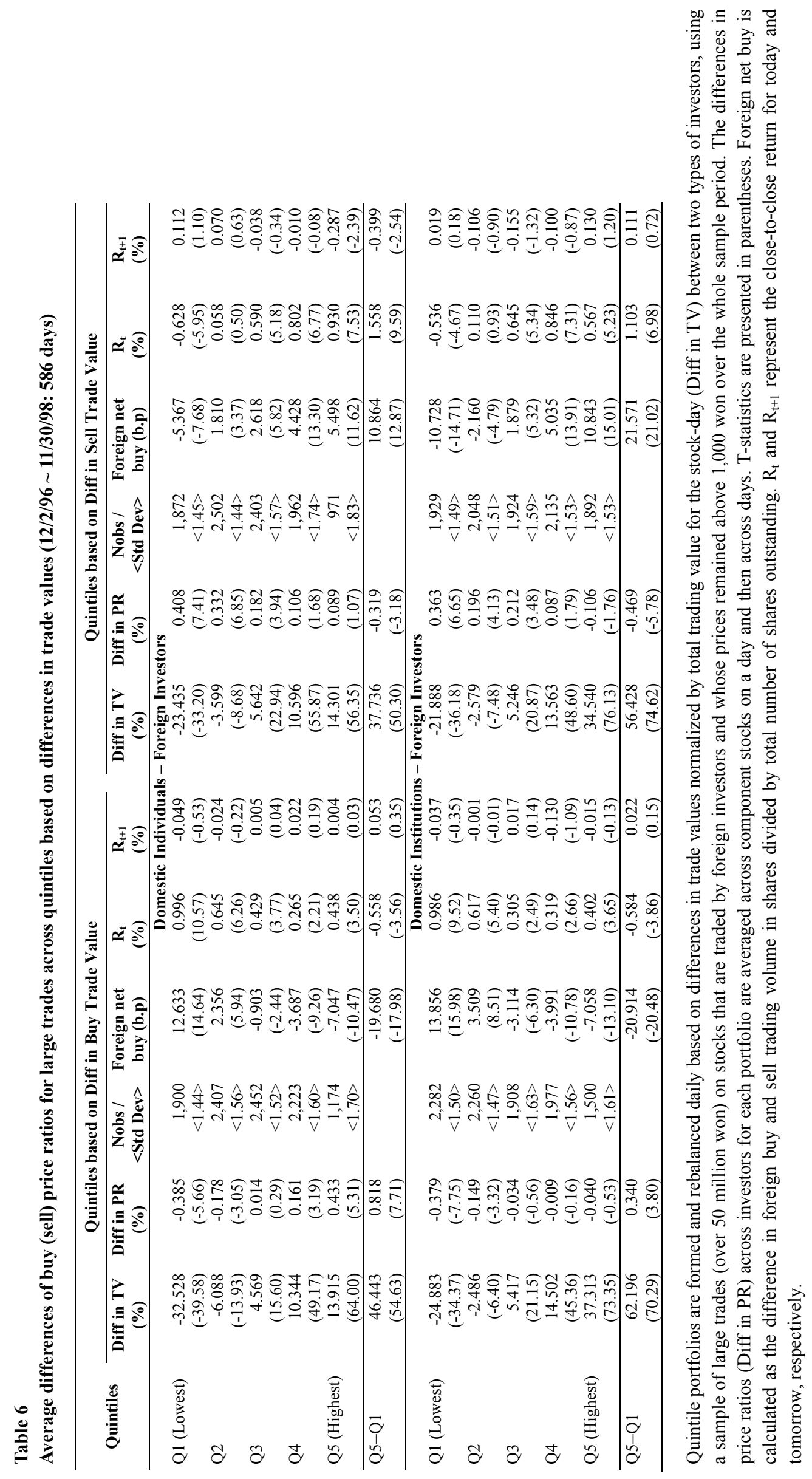

